\title{
Cell Type- and Layer-Specific Muscarinic Potentiation of Excitatory Synaptic Drive onto Parvalbumin Neurons in Mouse Prefrontal Cortex
}

\author{
(1)Tatiana B. Tikhonova, ${ }^{1}$ Takeaki Miyamae, ${ }^{1}$ Yelena Gulchina, ${ }^{1}$ DDavid A. Lewis, ${ }^{1}$ and ${ }^{-G u i l l e r m o ~}$ \\ Gonzalez-Burgos ${ }^{1}$
}

https://doi.org/10.1523/ENEURO.0208-18.2018

${ }^{1}$ Translational Neuroscience Program, Department of Psychiatry, University of Pittsburgh School of Medicine, Pittsburgh, PA 15261

\begin{abstract}
Cholinergic neuromodulation is thought to shape network activity in the PFC, and thus PFC-dependent cognitive functions. ACh may modulate the activity of parvalbumin-positive $\left(\mathrm{PV}^{+}\right)$neurons, which critically regulate cortical network function. However, the mechanisms of cholinergic regulation of $\mathrm{PV}^{+}$neuron activity, and particularly of the basket cell $(\mathrm{BC})$ versus chandelier cell $(\mathrm{ChC})$ subtypes, are unclear. Using patch clamp recordings in acute slices, we examined the effects of the ACh receptor (AChR) agonist carbachol on the excitatory synaptic drive onto BCs or ChCs in layers 2 to 6 of mouse PFC. Carbachol increased the frequency and amplitude of spontaneous EPSCs (sEPSCs) recorded from $\mathrm{PV}^{+}$BCs in layers 3-6, but not in BCs from layer 2. Moreover, carbachol did not change the sEPSCs in ChCs, which were located exclusively in layer 2. The potentiation of sEPSCs in layers 3-6 BCs was prevented by the $\mathrm{Na}^{+}$channel blocker tetrodotoxin and was abolished by the M1-selective muscarinic AChR antagonist pirenzepine. Thus, carbachol potentiates the activity-dependent excitatory drive onto $\mathrm{PV}^{+}$neurons via M1-muscarinic AChR activation in a cell type- and layer-specific manner. In current clamp recordings with synaptic transmission blocked, carbachol directly evoked firing in deep layer pyramidal neurons (PNs). In contrast, carbachol elicited deep layer BC firing indirectly, via glutamate-mediated synaptic drive. Our data suggest that ACh powerfully regulates PFC microcircuit function by facilitating the firing of PNs that synaptically recruit deep layer $\mathrm{PV}^{+} \mathrm{BC}$ activity, possibly shaping the patterns of network activity that contribute to cognitive function.
\end{abstract}

Key words: Prefrontal cortex; acetylcholine; EPSC; parvalbumin; interneuron; muscarinic receptor

\section{Significance Statement}

Cholinergic neuromodulation and parvalbumin-positive $\left(\mathrm{PV}^{+}\right)$neurons may be essential for regulation of PFC network activity. To determine whether cholinergic input modulates PFC network function via $\mathrm{PV}^{+}$ neurons, we examined the effects of the cholinergic agonist carbachol on the excitatory synaptic drive onto $\mathrm{PV}^{+}$neurons in mouse PFC. Carbachol, via M1 muscarinic ACh receptor activation, potentiated the excitatory synaptic currents onto $\mathrm{PV}^{+}$basket cells $(\mathrm{BCs})$ in deep cortical layers, but not onto superficial layer $\mathrm{BCs}$ or chandelier cells (ChCs). Carbachol directly elicited firing in deep layer pyramidal neurons (PNs) but $\mathrm{BC}$ activity was recruited indirectly, via synaptic glutamate-mediated excitatory drive. Our data suggest that cholinergic neuromodulation contributes to PFC-dependent cognitive function recruiting $\mathrm{PV}^{+}$neuron activity in a cell type- and layer-specific manner.

Received May 21, 2018; accepted October 22, 2018; First published October 31, 2018.

D.A.L. currently receives investigator-initiated research support from Pfizer and recently served as a consultant to Merck in the areas of target identification and validation and new compound development. T.B.T., T.M., Y.G., and G.G.-B. declare no competing financial interests. 


\section{Introduction}

Regulation of cortical network activity by ACh plays a crucial role in cognitive function (Ballinger et al., 2016). For example, PFC activity is strongly modulated by cholinergic input (Picciotto et al., 2012; Arnsten and Wang, 2016). In addition, ACh depletion in the PFC (Croxson et al., 2011), or intra-PFC infusion of ACh receptor (AChR) antagonists (Howe et al., 2017), disrupt performance in cognitive tasks. Despite this crucial role of $\mathrm{ACh}$, the mechanisms of cholinergic modulation of PFC network activity remain poorly understood.

Muscarinic receptor (mAChR) activation increases PFC pyramidal neuron $(\mathrm{PN})$ firing via direct depolarization and/or enhancing the intrinsic excitability of PNs (Obermayer et al., 2017; Baker et al., 2018; Radnikow and Feldmeyer, 2018). Many of the ACh effects on PNs, such as the excitatory mAChR response (McCormick and Prince, 1986; Gulledge et al., 2009), are layer dependent, specifically being stronger in deep layers (Obermayer et al., 2017; Radnikow and Feldmeyer, 2018). Deep layer PNs also show stronger nicotinic AChR-mediated responses (Poorthuis et al., 2013; Hedrick and Waters, 2015), which may be dependent on cortical region ( $\mathrm{He}-$ drick and Waters, 2015).

Relatively less is known about the effects of ACh on interneurons, particularly of the parvalbumin-positive $\left(\mathrm{PV}^{+}\right)$class (Muñoz and Rudy, 2014), which provide strong perisomatic inhibition onto PNs and are crucial for regulation of cortical network activity (Hu et al., 2014). Furthermore, the effects of ACh have not been compared between the two main subtypes of $\mathrm{PV}^{+}$neurons, basket cells (BCs) and chandelier cells (ChCs), which target the perisomatic $\mathrm{PN}$ membrane. Whereas $\mathrm{BCs}$ innervate the soma and proximal dendrites, ChCs target the axon initial segment (Somogyi et al., 1998; DeFelipe et al., 2013). Moreover, ChCs and BCs both display a fast-spiking phenotype in vitro (Hu et al., 2014) but exhibit different firing dynamics in vivo (Zhu et al., 2004; Klausberger and Somogyi, 2008; Massi et al., 2012; Viney et al., 2013). Thus, regulation of network activity by $\mathrm{PV}^{+}$neurons seems to involve a division of labor between ChCs and $\mathrm{BCs}$, but whether cell type-specific neuromodulation con-

Author contributions: T.B.T., T.M., Y.G., D.A.L., G.G.-B. designed research; T.B.T., T.M., Y.G., and G.G.-B. performed research; T.B.T., T.M., Y.G. and G.G.-B. analyzed data; T.B.T., D.A.L., and G.G.-B. wrote the paper.

This work was supported by National Institutes of Health Grants MH51234 and $\mathrm{P} 50 \mathrm{MH} 103204$.

T. B. Tikhonova's present address: Sechenov Institute of Evolutionary Physiology and Biochemistry, Russian Academy of Sciences, Saint Petersburg, Russia.

Acknowledgements: We thank Olga Krimer for her contribution with histochemical labeling and three-dimensional neuron reconstructions, and Diego Pafundo for useful comments on this manuscript.

Correspondence should be addressed to Guillermo Gonzalez-Burgos, Translational Neuroscience Program, Department of Psychiatry, University of Pittsburgh School of Medicine, W1647 Biomedical Science Tower, 200 Lothrop Street, Pittsburgh PA 15261, E-mail: gburgos@pitt.edu.

https://doi.org/10.1523/ENEURO.0208-18.2018

Copyright () 2018 Tikhonova et al.

This is an open-access article distributed under the terms of the Creative Commons Attribution 4.0 International license, which permits unrestricted use, distribution and reproduction in any medium provided that the original work is properly attributed. tributes to the different roles played by ChCs and BCs is unclear.

Given that AChR stimulation increases PN firing, it may also enhance the excitatory synaptic drive onto $\mathrm{PV}^{+}$ neurons, thus being essential for the regulation of PFC network activity via $\mathrm{PV}^{+}$neuron-mediated inhibition (Picciotto et al., 2012). To test whether AChR stimulation modulates the excitatory drive onto $\mathrm{PV}^{+}$neurons, we assessed the effects of the AChR agonist carbachol on spontaneous EPSCs (sEPSCs) recorded from $\mathrm{PV}^{+}$neurons in acute slices from mouse PFC. Consistent with previous findings that stimulation of $\mathrm{M} 1 \mathrm{mAChRs}$ facilitates deep layer PN firing (Carr and Surmeier, 2007), we found that carbachol increased the excitatory drive onto $\mathrm{PV}^{+}$neurons in layers 3-6, via an effect prevented by an M1-selective mAChR antagonist (pirenzepine) or by tetrodotoxin, a $\mathrm{Na}^{+}$channel blocker that inhibits action potential firing. In contrast, carbachol did not have effects on the excitatory drive onto $\mathrm{PV}^{+}$neurons located in layer 2. Analysis of the morphology of the recorded neurons revealed that all layers 3-6 $\mathrm{PV}^{+}$neurons were $\mathrm{BCs}$, whereas among the layer $2 \mathrm{PV}^{+}$cells, $\sim 50 \%$ were ChCs and $\sim 50 \%$ were BCs. Current clamp recordings showed that $\mathrm{mAChR}$ activation can directly evoke firing in layer $5 \mathrm{PNs}$, but elicits layers 3-6 BC firing indirectly, via glutamatemediated synaptic input. Thus, our data show that mAChRs enhance the excitatory drive onto $\mathrm{PV}^{+}$neurons in a cell type- and layer-specific manner, selectively recruiting the activity of BCs in deep layers of PFC.

\section{Materials and Methods}

All animal procedures were performed in accordance with the guidelines of the National Institutes of Health Guide for Care and Use of Laboratory Animals and were approved by our institution's Animal Care and Use Committee.

\section{Slice preparation}

The experiments were performed using G42 mice of both sexes (The Jackson Laboratory, stock number 007677; RRID:IMSR_JAX:007677) which express green fluorescent protein (GFP) exclusively in $\mathrm{PV}^{+}$interneurons (Chattopadhyaya et al., 2004). The mice (aged postnatal days 23-42) were quickly decapitated under deep isoflurane anesthesia, and the brain was removed and placed in ice-cold slicing solution containing: $120 \mathrm{mM}$ choline chloride, $2.5 \mathrm{mM} \mathrm{KCl}, 1.2 \mathrm{mM} \mathrm{Na}_{2} \mathrm{HPO}_{4}, 25 \mathrm{mM} \mathrm{NaHCO}_{3}, 20$ $\mathrm{mM}$ glucose, $1.3 \mathrm{mM}$ ascorbate, $2.4 \mathrm{mM}$ pyruvate, $7 \mathrm{mM}$ $\mathrm{MgCl}_{2}$, and $0.5 \mathrm{mM} \mathrm{CaCl}_{2} ; \mathrm{pH}$ 7.3-7.4, and continuously bubbled with $95 \% \mathrm{O}_{2}-5 \% \mathrm{CO}_{2}$. In the experiments testing the effects of tetrodotoxin, atropine, or pirenzepine, the slices were prepared in a slicing solution containing: $200 \mathrm{mM}$ sucrose, $15 \mathrm{mM} \mathrm{NaCl}, 1.9 \mathrm{mM} \mathrm{KCl}, 1.2 \mathrm{mM}$ $\mathrm{Na}_{2} \mathrm{HPO}_{4}, 33 \mathrm{mM} \mathrm{NaHCO}, 10 \mathrm{mM}$ glucose, $2 \mathrm{mM}$ kynurenic acid, $6 \mathrm{mM} \mathrm{MgCl}_{2}$, and $0.5 \mathrm{mM} \mathrm{CaCl}_{2} ; \mathrm{pH}$ 7.3-7.4, continuously bubbled with $95 \% \quad \mathrm{O}_{2}-5 \% \quad \mathrm{CO}_{2}$. Coronal brain slices (300 $\mu \mathrm{m}$ thick) were prepared from the frontal cortex using a vibrating microtome (VT1000S or VT1200S, Leica Microsystems) and incubated for $5 \mathrm{~min}$ at $36^{\circ} \mathrm{C}$ in oxygenated $\left(95 \% \mathrm{O}_{2}-5 \% \mathrm{CO}_{2}\right)$ artificial $\mathrm{CSF}$ (ACSF; pH 7.4) solution containing: $125 \mathrm{mM} \mathrm{NaCl}, 2.5 \mathrm{mM}$ 
$\mathrm{KCl}, 1.25 \mathrm{mM} \mathrm{Na}_{2} \mathrm{HPO}_{4}, 10 \mathrm{mM}$ glucose, $25 \mathrm{mM} \mathrm{NaHCO}_{3}$, $0.4 \mathrm{mM}$ ascorbate, $1 \mathrm{mM} \mathrm{MgCl}_{2}$, and $2 \mathrm{mM} \mathrm{CaCl}_{2}$. The slices were allowed to equilibrate at room temperature for at least 30 min before they were transferred to the recording chamber. The potentiation of sEPSC frequency by $20 \mu \mathrm{M}$ carbachol did not differ between layer 3-6 BCs recorded from slices prepared with choline-based slicing solution (baseline: $9.3 \pm 7.7 \mathrm{~Hz}$; carbachol: $33.1 \pm 26 \mathrm{~Hz}, n=7$ ) versus the sucrose-based slicing solution [baseline: $14.1 \pm$ $7.4 \mathrm{~Hz}$; carbachol: $32.7 \pm 8.6 \mathrm{~Hz}, n=5$; carbachol effect: $F_{(1,10)}=18.077, p=0.00168$; Slicing solution effect $F_{(1,10)}=$ $0.255, p=0.6248$, two-way repeated measures (RM) ANOVA].

\section{Electrophysiological recordings and data analysis}

Recordings were performed in a submersion chamber superfused at a rate of $5 \mathrm{ml} / \mathrm{min}$ (Hajos et al., 2009) with oxygenated ACSF at $30-32^{\circ} \mathrm{C}$, containing $10 \mu \mathrm{M}$ SR-

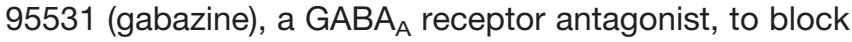
inhibitory postsynaptic currents. In some experiments 10 $\mu \mathrm{M}$ 6-cyano-7-nitroquinoxaline-2,3-dione (CNQX), an AMPA/kainate antagonist, was added to block excitatory postsynaptic currents. We found that the fast perfusion rate significantly improved the stability of the effects of carbachol, as reported previously (Hajos et al., 2009). Whole-cell recordings were obtained from $\mathrm{PV}^{+}$neurons in the medial frontal cortex [infralimbic (IL), prelimbic (PL), and anterior cingulate (AC) regions]. Neurons were identified by the presence of GFP fluorescence, using Olympus or Zeiss microscopes equipped with epifluorescence, infrared illumination, differential interference contrast, and a CCD video camera (EXi Aqua, Q-Imaging). Pipettes pulled from borosilicate glass (resistance: 3-6 M $\Omega$ ) were filled with the following solution: $120 \mathrm{mM}$ potassium gluconate, $10 \mathrm{mM} \mathrm{KCl}, 10 \mathrm{mM}$ HEPES, $0.2 \mathrm{mM}$ EGTA, 4.5 mM MgATP, $0.3 \mathrm{mM}$ NaGTP, $14 \mathrm{mM}$ sodium phosphocreatine; the $\mathrm{pH}$ was adjusted to 7.2-7.4 using $\mathrm{KOH}$. Biocytin $(0.5 \%)$ was added to the pipette solution for later morphologic identification. Recordings were obtained with Multiclamp $700 \mathrm{~B}$ or $700 \mathrm{~A}$ amplifiers (Molecular Devices). Signals were low-pass filtered at $6 \mathrm{kHz}$ and digitized at 10 or $20 \mathrm{kHz}$ using a Power 1401 data acquisition interface (Cambridge Electronic Design). Data acquisition was performed using Signal 5 software (Cambridge Electronic Design), running custom-made scripts.

\section{Voltage clamp}

$\mathrm{PV}^{+}$neurons were recorded while holding their membrane potential at $-75 \mathrm{mV}$ and in the presence of gabazine. In these conditions, the EPSCs recorded from $\mathrm{PV}^{+}$ neurons were entirely blocked by the AMPA receptor antagonist CNQX (data not shown). The pipette capacitance $(\mathrm{Cp})$ was compensated and the series resistance (Rs) was continuously monitored, but Rs compensation was not used. Only recordings with an initial Rs $<15 \mathrm{M} \Omega$ were used for analysis. The stability of Rs was measured using the current transient evoked by a $50 \mathrm{~ms}-5 \mathrm{mV}$ voltage step, delivered every $5 \mathrm{~s}$, and recordings were not used for data analysis if the Rs changed by $>15 \%$ of the initial value.
For each recorded $\mathrm{PV}^{+}$neuron, sEPSCs were detected in 20-s time windows, every min, for $\geq 5$ min before the application of carbachol, during carbachol application, and through 15 min of washout. EPSCs were detected and analyzed using Mini Analysis software (Synaptosoft), with an amplitude threshold of 4-6 pA, area threshold of $4 \mathrm{pA} / \mathrm{ms}$ and setting the average baseline before EPSC onset to 2-10 ms. The detected SEPSCs were visually inspected and used to estimate the mean peak sEPSC amplitude and SEPSC frequency. The mean sEPSC frequency was calculated for each 20 -s time window analyzed, from the number of sEPSCs detected in each time window and expressed in $\mathrm{Hz}$. The mean sEPSC amplitude was calculated, for each recorded neuron, as the average of the amplitudes of all sEPSCs detected, during control, carbachol or washout periods.

\section{Current clamp}

Cells included in this study had an initial resting membrane potential of -60 to $-80 \mathrm{mV}$. Current clamp recordings from $\mathrm{PV}^{+}$neurons and pyramidal cells in layers 3-6 were conducted in the continuous presence of the GABA $A_{A}$ receptor antagonist gabazine $(10 \mu \mathrm{M})$ and the glutamate receptor antagonist CNQX (10 or $20 \mu \mathrm{M}$ ), except for some recordings in which CNQX was omitted, as indicated. The $\mathrm{Rs}$ and $\mathrm{Cp}$ were monitored and cancelled using the bridge balance and capacitance neutralization circuits. The rheobase was estimated as the smallest current step amplitude eliciting at least one action potential in three repetitions of that current step. Subsequently, depolarizing current steps (500 ms duration) were injected in $10 \mathrm{pA}$ increments from $10 \mathrm{pA}$ below rheobase to +30 or $+40 \mathrm{pA}$ above rheobase continuously, throughout the duration of the experiment. Resting membrane potential was determined by averaging the values measured from a $50 \mathrm{~ms}$ window placed before a hyperpolarizing current step (-50 $\mathrm{pA}, 50 \mathrm{~ms}$ ) used to monitor stability of the input resistance and membrane time constant. The frequency of action potentials elicited by carbachol independent of current injection was measured in the 200- to 500-ms window preceding the injected current steps, as indicated in Figures 10,11 . The depolarizing current step injection was used to test the possibility that carbachol increases the response to the excitatory current steps without directly depolarizing the cells' membrane potential. Baseline was collected for $\geq 5$ min before bath application of carbachol $(20 \mu \mathrm{M})$ for $5 \mathrm{~min}$. In some current clamp recordings from $\mathrm{PV}^{+}$cells or PNs, atropine $(10 \mu \mathrm{M})$ or pirenzepine $(1 \mu \mathrm{M})$ were continuously bath applied.

\section{Histologic processing and morphologic reconstruction of biocytin-filled neurons}

The $\mathrm{PV}^{+}$neurons filled with $0.4-0.5 \%$ biocytin during recordings were visualized and reconstructed using standard procedures. Briefly, after recordings, the slices were immersed in $4 \% \mathrm{p}$-formaldehyde in $0.1 \mathrm{M}$ PBS for 24-72 $\mathrm{h}$ at $4^{\circ} \mathrm{C}$. The slices were stored at $-80^{\circ} \mathrm{C}$ in cryoprotection solution (33\% glycerol, 33\% ethylene glycol, in $0.1 \mathrm{M}$ PBS) until processed. To visualize biocytin, the slices were resectioned at $60 \mu \mathrm{m}$, incubated with $1 \%$ $\mathrm{H}_{2} \mathrm{O}_{2}$, and immersed in blocking serum containing $0.5 \%$ 
Triton $\mathrm{X}-100$ for $2-3 \mathrm{~h}$ at room temperature. The tissue was then rinsed and incubated with the avidin-biotinperoxidase complex (1:100; Vector Laboratories) in PBS for $4 \mathrm{~h}$ at room temperature. Sections were rinsed, stained with the Nickel-enhanced 3,3'-diaminobenzidine chromogen, mounted on gelatin-coated glass slides, dehydrated, and coverslipped. Three-dimensional reconstructions were performed using the Neurolucida tracing system (MBF Bioscience). Here we report data on the morphologic reconstructions of $\mathrm{PV}^{+}$neurons for which we tested the effects of carbachol on sEPSCs.

ChCs are morphologically defined by an axonal arbor with abundant cartridges, short rows of boutons aligned vertically and connected by axonal segments of thin diameter, which reflect targeting of the axon initial segment of neighbor pyramidal cells (DeFelipe et al., 2013). ChC axons typically display between two and nine boutons per cartridge (Inan et al., 2013). In contrast to ChCs, the axons of BCs lack cartridges, reflecting their targeting of soma and dendrites, but not the axon initial segment, of their postsynaptic pyramidal cells (DeFelipe et al., 2013).

\section{Laminar location of the somata of the recorded $\mathrm{PV}^{+}$ neurons}

GFP-positive $\left(\mathrm{GFP}^{+}\right) \mathrm{PV}^{+}$neurons were selected for recording based on their laminar location as follows. Due to the low neuron density present in layer 1 , the location of the layer 1-2 border was easily distinguished under differential interference contrast imaging of the slices in the recording chamber. To record from $\mathrm{PV}^{+}$neurons of $\mathrm{ChC}$ subtype, we targeted for recording $\mathrm{GFP}^{+}$cells in superficial layer 2 near the border with layer 1, since previous studies showed that ChCs are abundant at this laminar location, where BCs are abundant as well (Woodruff et al., 2011; Miyamae et al., 2017). To target for recording $\mathrm{PV}^{+}$ cells in layers 3-6, first we estimated the thickness of layer 1 using low magnification images of the slices in the recording chamber (measured in 10 slices, the layer 1 thickness was, mean \pm SEM, $141 \pm 39 \mu \mathrm{m}$, range: $90-$ $205 \mu \mathrm{m})$. In the rodent PFC, the border between layers 2 and 3 is less well defined than the layer $1 / 2$ border and cannot be reliably identified in the slices during the electrophysiological recording experiments. However, the average thickness of layer 2 is similar to the thickness of layer 1 (Gabbott et al., 1997; Ding et al., 2001; Van De Werd et al., 2010). Therefore, using the location of the layer $1 / 2$ border in each slice, to record from $\mathrm{PV}^{+}$cells in layers 3-6, we targeted $\mathrm{GFP}^{+}$cells with somata located at a distance from the pial surface greater than $\sim 2.5$ times the thickness of layer 1 . Using this procedure, we did not target for recordings $\mathrm{GFP}^{+}$neurons with soma located in deep layer 2 and superficial layer 3 (Fig. 1), where all PFC $\mathrm{PV}^{+}$neurons are BCs (Miyamae et al., 2017; Pafundo et al., 2018) and ChCs are absent (Taniguchi et al., 2013). The laminar position of the deep layer $\mathrm{PV}^{+}$neurons was determined using approximate laminar boundaries, as follows. In the rodent PFC, the border between layers 3 and 5 is located at approximately half the distance between the pia and the white matter, while the border between layers 5 and 6 is located at approximately half

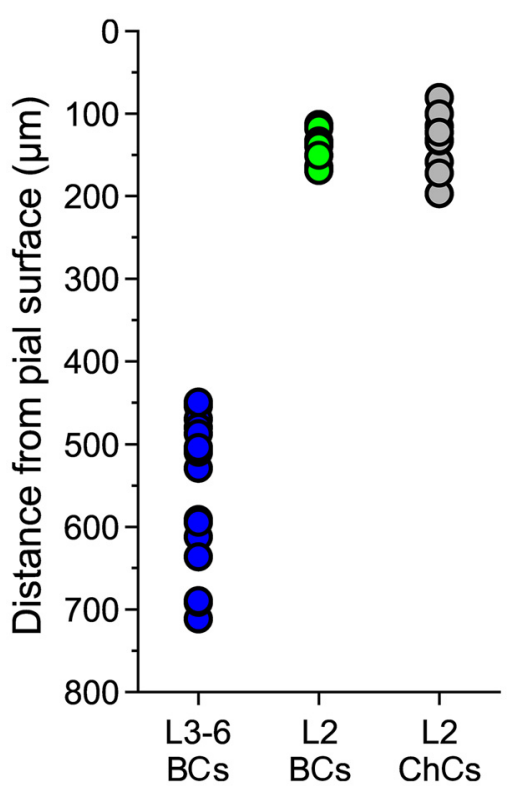

Figure 1. Distance between the pial surface and the $\mathrm{PV}^{+}$cell somata for BCs of layers 3-6 (L3-6 BCs), for BCs of layer 2 near the border with layer 1 (L2 BCs) and for ChCs of layer 2 near the border with layer 1 (L2 ChCs).

the distance between the layers 3-5 border and the white matter border (Gabbott et al., 1997; Ding et al., 2001; Van De Werd et al., 2010).

\section{Statistical analysis}

The data were expressed as mean \pm SEM. The significance of the effects of carbachol on SEPSC frequency or amplitude was assessed using one-way RM ANOVA, or one-way RM mixed model ANOVA, and in some cases paired $t$ tests. To assess the significance of differences between group means, we first calculated the residuals for each variable, and performed Shapiro-Wilk tests of normality of the residuals. When necessary depending on the $p$ value of the Shapiro-Wilk test, we employed natural logarithm transformation of the data. When the ShapiroWilk tests were significant before or after log transformation, we used rank transformation of the data. The results of the Shapiro-Wilk tests are reported, for data illustrated in the figures, in the statistics table (Table 1), and otherwise in the text. In all figures, values are shown without transformation. The statistical analysis was performed using SPSS 20 (IBM Corp.).

\section{Results}

To assess the effects of AChR activation on excitatory drive onto $\mathrm{PV}^{+}$neurons, we recorded sEPSCs from $\mathrm{GFP}^{+}$ cells in the PFC of G42 mice, which express GFP selectively in $\mathrm{PV}^{+}$neurons (Chattopadhyaya et al., 2004; Buchanan et al., 2012; Sippy and Yuste, 2013). Previous studies reported that whereas $\mathrm{PV}^{+} \mathrm{BCs}$ are located across all layers, ChCs are concentrated or exclusively located near the border between layers 1 and 2 (Woodruff et al., 2011; Miyamae et al., 2017). Thus, we targeted for recording GFP ${ }^{+}$cells with soma located in deep layer 3 to layer 6 (L3-6 cells), or in layer 2 near the border with layer 
Table 1. Statistics table

\begin{tabular}{|c|c|c|c|}
\hline Data & Data Structure (Shapiro-Wilk test, $p$ value) & Statistical test & $p$ value \\
\hline Figure $2 E$ & $0.016^{*}$ & $\begin{array}{l}\text { One-way RM ANOVA } \\
F_{(2,13.01)}=27.26^{* * *}\end{array}$ & $<0.001^{* * * *}$ \\
\hline Figure $2 F$ & 0.721 & $\begin{array}{l}\text { One-way RM ANOVA } \\
F_{(2,12.89)}=5.49^{* * *}\end{array}$ & 0.019 \\
\hline Figure $3 C$ & 0.146 & One-way RM ANOVA $F_{(2,16)}=0.79$ & 0.469 \\
\hline Figure $3 D$ & 0.988 & One-way RM ANOVA $F_{(2,16)}^{(2,16)}=5.54$ & 0.017 \\
\hline Figure $4 C$ & $0.080^{*}$ & $\begin{array}{l}\text { One-way RM ANOVA } \\
F_{(2,19.5)}=2.53^{* * *}\end{array}$ & 0.106 \\
\hline Figure $4 D$ & 0.648 & $\begin{array}{l}\text { One-way RM ANOVA } \\
F_{(2,15.4)}=2.89^{* *}\end{array}$ & 0.086 \\
\hline Figure $6 B, C$ & $0.0795^{*}$ & $\begin{array}{l}\text { Two-way ANOVA, } \\
\text { Cell type: } F_{(2,17)}=7.647 \text {, } \\
\text { Area: } F_{(2,17)}=1.101 \\
\text { Interaction: } F_{(4,17)}=0.191\end{array}$ & $\begin{array}{l}p=0.00428 ; p=0.355 \\
p=0.939\end{array}$ \\
\hline Figure $7 C$ & 0.357 & $F_{(2,20)}=4.634$ & $p=0.022$ \\
\hline Figure $7 D$ & 0.178 & $F_{(2,20)}=1.281$ & $p=0.299$ \\
\hline Figure $8 C$ & $0.101^{*}$ & One-way RM ANOVA $F_{(2,16.46)}=0.81^{* *}$ & 0.461 \\
\hline Figure $8 D$ & 0.517 & One-way RM ANOVA $F_{(2,16.11)}=0.52^{* * *}$ & 0.602 \\
\hline Figure $9 C$ & $0.0485^{*}$ & One-way RM ANOVA $F_{(2,27.3)}=0.565^{* *}$ & $p=0.575^{* * *}$ \\
\hline Figure $9 D$ & $0.004^{*}$ & One-way RM ANOVA $F_{(2,27.3)}^{(27 .)}=0.0095^{* *}$ & $p=0.991^{* * *}$ \\
\hline Figure $10 C$ & 0.787 & $\begin{array}{l}\text { Paired sample } t \text { test } \\
t_{(6)}=-5.041\end{array}$ & 0.0023 \\
\hline Figure $10 E$ & 0.458 & One-way RM ANOVA $F_{(2,8)}=8.555$ & 0.01 \\
\hline Figure $11 B$ & 0.1707 & One-way RM ANOVA $F_{(1,8)}^{(2,0)}=6.579$ & 0.033 \\
\hline Figure $11 D$ & $0.0439^{*}$ & $\begin{array}{l}\text { One-way RM ANOVA } \\
F_{(2,8)}=1.500\end{array}$ & $0.280^{* * *}$ \\
\hline
\end{tabular}

* Shapiro-Wilk test performed on the residuals of the log-transformed data.

*** Mixed model RM ANOVA.

**** RM ANOVA was performed using the data rank transformation (see Materials and Methods, Statistical analysis)

1 ( $\mathrm{L} 2$ cells). The GFP ${ }^{+}$neurons were filled with biocytin during recordings to determine the morphologic subtype of each recorded cell. We examined a total of 82 GFP $^{+}$ neurons: 63 L3-6 cells, and 19 L2 cells. As reported in earlier studies (Woodruff et al., 2011; Miyamae et al., 2017), ChCs were found exclusively near the border between layers 1 and 2, where they comprised nearly half $(10 / 19)$ of the L2 cells, as the rest of L2 GFP $^{+}$cells $(9 / 19)$ were BCs. On the other hand, all L3-6 GFP ${ }^{+}$neurons were $\mathrm{BCs}$, consistent with a previous study of mouse PFC (Miyamae et al., 2017).

The effects of AChR stimulation on excitatory drive were assessed in the following manner: after $\geq 5 \mathrm{~min}$ of baseline sEPSC recordings, carbachol $(20 \mu \mathrm{M})$ was perfused for $10 \mathrm{~min}$, followed by $15 \mathrm{~min}$ of washout. Figure $2 A$ shows morphologic reconstructions of the axonal arbor and dendritic tree of the seven L3-6 BCs for which we tested the effects of carbachol on SEPSCs. Carbachol caused a marked increase in sEPSC frequency in L3-6 BCs (Fig. 2B), which was accompanied by an increase in the mean sEPSC amplitude (Fig. 2C). The effect of carbachol developed within 2-3 min of application and was rapidly reversed by washout (Fig. 2D). Both the increases in sEPSC frequency (Fig. 2E) and sEPSC amplitude (Fig. $2 F)$ by carbachol were significant, and reversed significantly with washout (one-way RM mixed model ANOVA, sEPSC frequency: $F_{(2,13.01)}=27.26, p<0.001$, sEPSC amplitude: $\left.F_{(2,12.89)}=5.486, p=0.019\right)$.

Figure $3 A$ shows reconstructions of the axonal arbor and dendritic tree of two representative examples of the L2 BCs $(n=9)$ for which we tested the actions of carba- chol on sEPSCs (Fig. 3B). In contrast to the effects observed in L3-6 BCs, carbachol did not significantly increase the sEPSC frequency (Fig. $3 C, D$ ) or sEPSC amplitude (Fig. 3E) in L2 BCs, whereas a small but significant decline in sEPSC amplitude was observed between baseline and washout periods (one-way RM ANOVA, SEPSC frequency: $F_{(2,16)}=0.794, p=0.469$, sEPSC amplitude: $\left.F_{(2,16)}=5.541, p=0.017\right)$.

Figure $4 A$ shows reconstructions of the axonal arbor and dendritic tree of three representative examples of the L2 ChCs $(n=10)$ tested with carbachol during sEPSC recordings. In L2 ChCs, carbachol application did not change the sEPSCs (Fig. 4B), in contrast to the increase observed in L3-6 BCs. Neither the sEPSC frequency (Fig. $4 C, D$ ) nor sEPSC amplitude (Fig. 4E) were significantly affected by carbachol in L2 ChCs (one-way RM mixed model ANOVA, sEPSC frequency: $F_{(2,19.5)}=2.53, p=$ 0.106 , sEPSC amplitude: $\left.F_{(2.154)}=2.89, p=0.086\right)$. The data showing that carbachol increases the SEPSC frequency and amplitude in L3-6 BCs but not in L2 BCs or L2 ChCs suggest that AChR stimulation increases the excitatory drive onto $\mathrm{PV}^{+}$neurons in a cell-type and layerspecific manner.

The marked contrast between the strong potentiation by carbachol of excitatory synaptic input in L3-6 BCs versus the absence of significant potentiation in L2 BCs or L2 ChCs prompted us to assess if these differences have a correlate in the morphology of the dendritic tree, the main site of excitatory input onto $\mathrm{PV}^{+}$neurons (Gulyás et al., 1999; Kameda et al., 2012). Quantitative analysis of the $\mathrm{PV}^{+}$neuron dendrites is presented in Figure 5. The 
A

pial surface

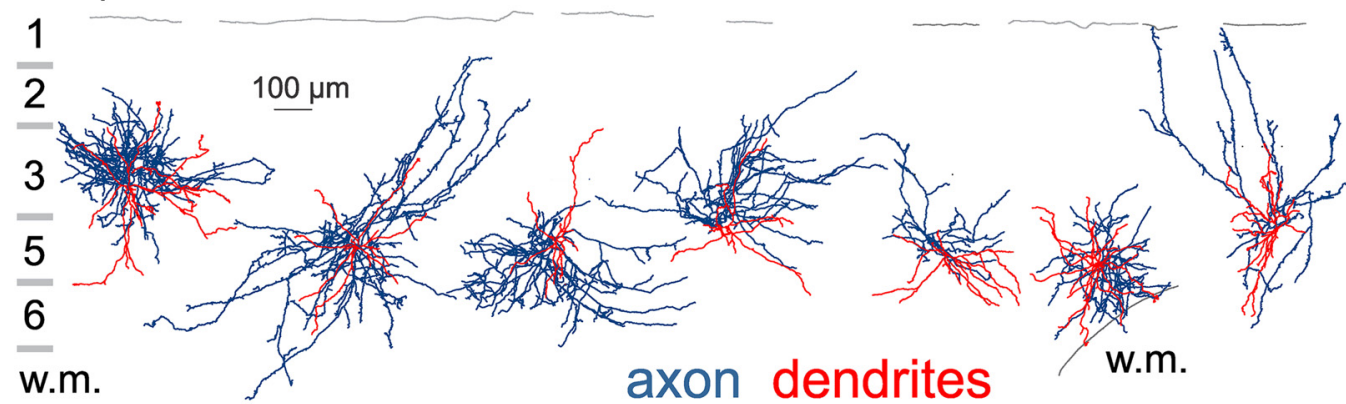

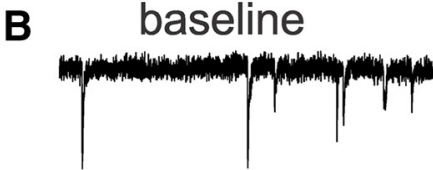

C
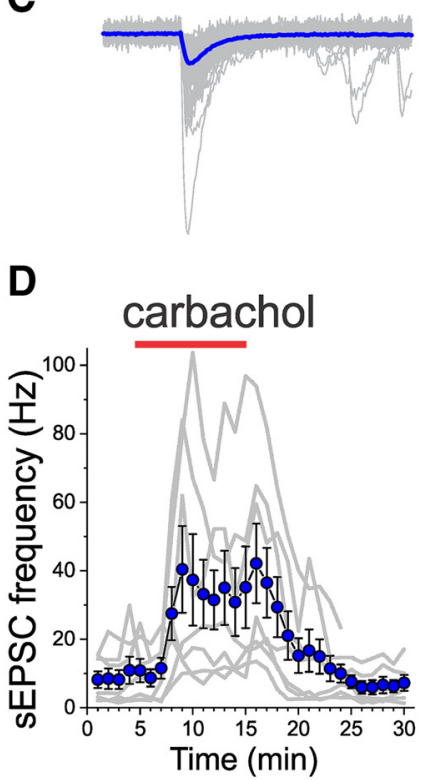

E

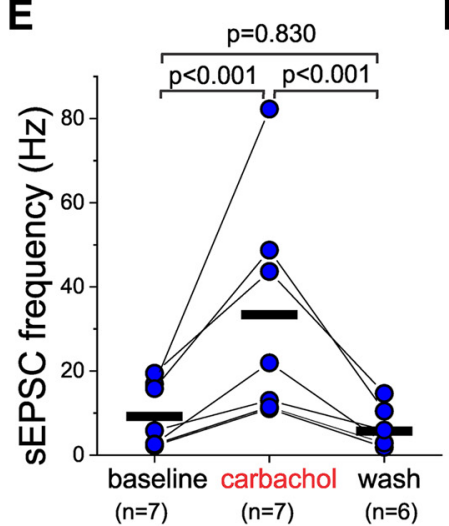

carbachol
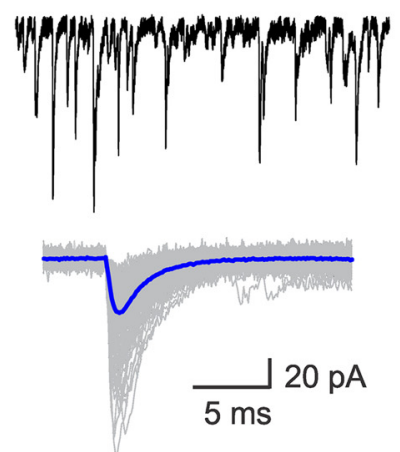

wash
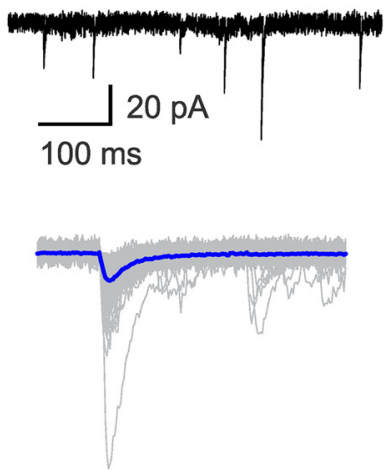

$\mathbf{F}$

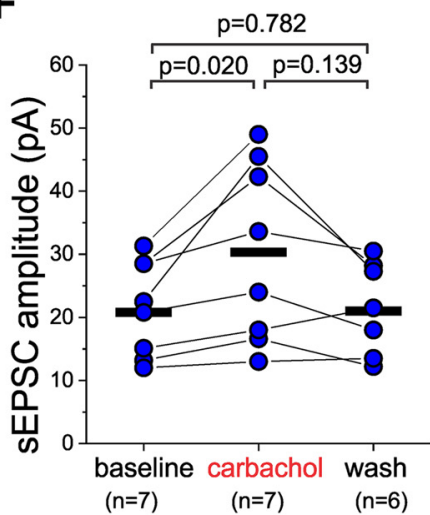

Figure 2. Effects of the AChR agonist carbachol on sEPSCs recorded from layers 3-6 $\mathrm{PV}^{+} \mathrm{BCs}$. $\boldsymbol{A}$, Examples of the morphology of layers 3-6 $\mathrm{PV}^{+} \mathrm{BCs}$, with their somata aligned relative to the pial surface (gray line), and displayed relative to the approximate boundaries of cortical layers. The dendritic tree is shown in red and the axonal arbor in blue. For a BC on the right part of this panel, the gray line at the bottom shows the border between layer 6 and white matter (w.m.). B, Examples of sEPSCs recorded from a layer 5 BC before (baseline), during $20 \mu \mathrm{M}$ carbachol application (carbachol), and after washout (wash). C, Examples of individual sEPSCs (gray traces) are shown superimposed aligned by their rise time, together with an average sEPSC (blue traces) obtained for each condition indicated in $\boldsymbol{B}$. Approximately 200 consecutive sEPSCs were averaged. $\boldsymbol{D}$, Time-course plot illustrating the effects of a 10-min application of $20 \mu \mathrm{M}$ carbachol on sEPSC frequency. The gray lines show the data for individual L3-6 BCs. The symbols show mean \pm SEM $(n=7)$. The sEPSC frequency was measured in $20 \mathrm{~s}$ time windows every $60 \mathrm{~s}$. $\boldsymbol{E}$, Carbachol had significant effects on sEPSC frequency when estimated at the last $20 \mathrm{~s}$ before carbachol application (baseline), the last $20 \mathrm{~s}$ before beginning of washout, and after $\geq 10$ min of washout (One-way RM mixed model ANOVA, $F_{(2,13.01)}=27.26, p<0.001$, shown in the figure are the $p$ values for Sidak-corrected post hoc pairwise comparisons). The black horizontal bars indicate the mean value for each sample. $\boldsymbol{F}$, Carbachol had significant effects on SEPSC amplitude when estimated between the last $20 \mathrm{~s}$ before carbachol application (baseline), the last 20 $s$ before beginning of washout, and after $\geq 10 \mathrm{~min}$ of washout (one-way RM ANOVA mixed model, $F_{(2,12.89)}=5.486, p=0.019$; shown in figure are the results of Sidak-corrected, post hoc pairwise comparisons). The black horizontal bars indicate the mean value for each sample. 
A

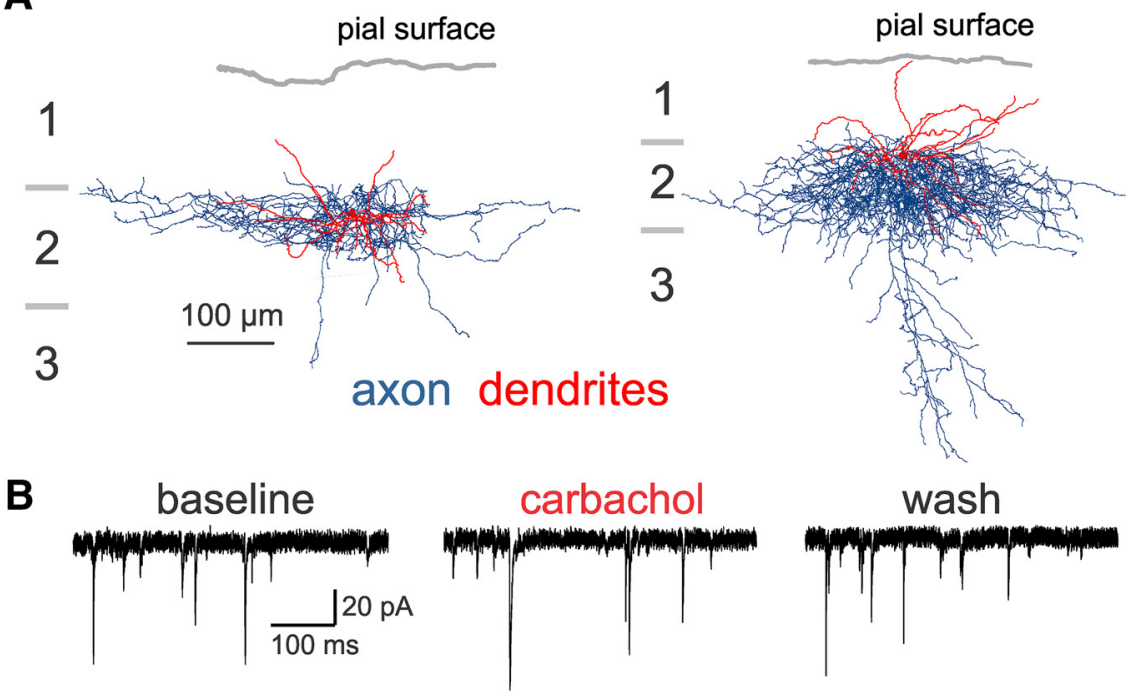

C

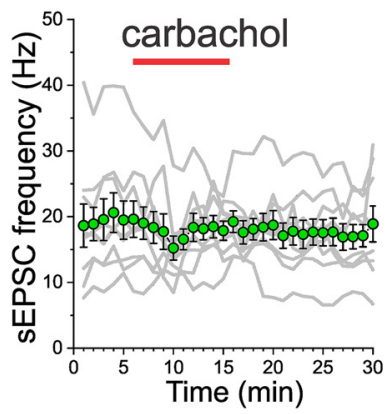

D

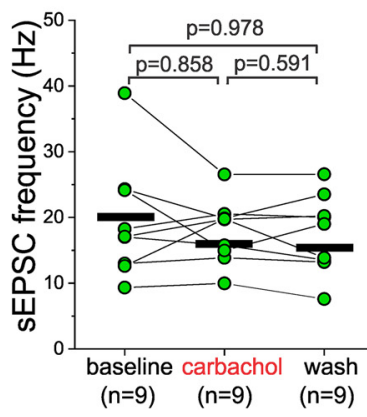

E

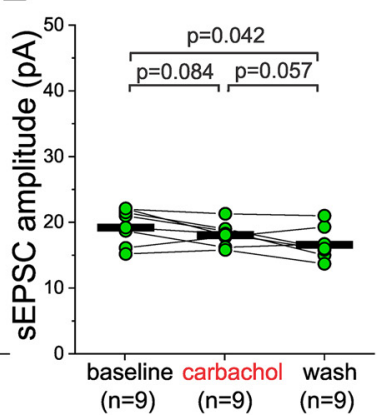

Figure 3. Effects of carbachol on sEPSCs recorded from layer $2 \mathrm{PV}^{+} \mathrm{BCs}$ with soma near the border with layer 1. $\boldsymbol{A}$, Examples of the morphology of layer $2 \mathrm{PV}^{+} \mathrm{BCs}$, with their somata aligned relative to the pial surface (gray line). The dendritic tree is shown in red and the axonal arbor in blue. Note that the BC dendrites are nearly evenly distributed between layers 1 and 2 , and that the distal tips of the $\mathrm{BC}$ dendrites in layer 1 mostly end far from the pial surface. $\boldsymbol{B}$, Examples of sEPSCs recorded from a layer 2 BC before (baseline), during $20 \mu \mathrm{M}$ carbachol application (carbachol), and after washout (wash). $\boldsymbol{C}$, Time-course plot illustrating the effects of a 10 min application of $20 \mu \mathrm{M}$ carbachol on sEPSC frequency. The gray lines show the data for individual BCs. The symbols show mean \pm $\mathrm{SEM}, n=9$. The sEPSC frequency was measured in $20 \mathrm{~s}$ time windows every $60 \mathrm{~s}$. $\boldsymbol{D}$, Carbachol did not have significant effects on sEPSC frequency when estimated $20 \mathrm{~s}$ before carbachol application (baseline), the last $20 \mathrm{~s}$ before beginning of washout, and after $\geq 10$ min of washout (one-way RM ANOVA, $F_{(2,16)}=0.794, p=0.469$; shown in figure are the results of Sidak-corrected, post hoc pairwise comparisons). The black horizontal bars indicate the mean value for each sample. $\boldsymbol{E}$, Carbachol did not significantly increase the sEPSC amplitude when estimated $20 \mathrm{~s}$ before carbachol application (baseline), the last $20 \mathrm{~s}$ before beginning of washout, and after $\geq 10$ min of washout (one-way RM ANOVA, $F_{(2,16)}=5.541, p=0.017$; shown in figure are the results of Sidak-corrected, post hoc pairwise comparisons). The black horizontal bars indicate the mean value for each sample.

dendritic trees of individual L3-6 BCs, L2 BCs and L2 ChCs were superimposed and aligned, in the $y$-axis, relative to the pial surface and centered, in the $x$-axis, by the location of the soma (Fig. 5A). Polar histograms of distribution of the dendritic length relative to the cell body showed that L3-6 BC dendrites extend in an approximately multipolar fashion, and in a manner largely confined to the deep cortical layers (Fig. $5 B$ ). The dendrites of L2 BCs also extended in a multipolar manner, distributing branches mainly in layers 2 and 1 (Fig. 5B). In contrast, L2 $\mathrm{ChC}$ dendrites mostly extended above the cell soma into layer 1 (Fig. 5B), as in somatosensory cortex (Woodruff et al., 2011). Whereas the total dendrite length (mean \pm SEM) did not differ significantly between $\mathrm{PV}^{+}$neuron subtypes (L3-6 BCs: $3374 \pm 517 \mu \mathrm{m}, n=7$; L2 BCs: $2439 \pm 262 \mu \mathrm{m}, n=5$; L2 ChCs: $2016 \pm 453 \mu \mathrm{m}, n=5$;
$F_{(2,14)}=2.452, p=0.122$, one-way ANOVA, Shapiro-Wilk $p=0.3419$ ), the distribution of dendrite length as a function of distance from the pial surface differed markedly between L3-6 BCs and L2 BCs or L2 ChCs (Fig. 5C). The dendrites of L2 ChCs were largely restricted to layer 1 , and only 1 of $5 \mathrm{ChCs}$ extended dendritic branches deeper than $300 \mu \mathrm{m}$ from the pial surface (Fig. 5 C). For ChCs, the percentage of total dendrite length located at a distance $\leq 300 \mu \mathrm{m}$ from the pial surface was $98.6 \pm 1.4 \%$ (mean \pm SEM, $n=5$, range: $93-100 \%)$. Compared to ChCs, L2 BCs had dendrites more evenly distributed above and below the cell soma (Fig. $5 B$ ), yet L2 BC dendrites were largely confined to layer 1 and superficial layer 2 , since $93.2 \pm 3.8 \%$ of the $\mathrm{L} 2 \mathrm{BC}$ dendritic tree (mean \pm SEM, $n=5$, range: $78-100 \%$ ) was found at a distance $\leq 300$ $\mu \mathrm{m}$ from the pial surface. In contrast, only $2.1 \pm 1.0 \%$ 
A

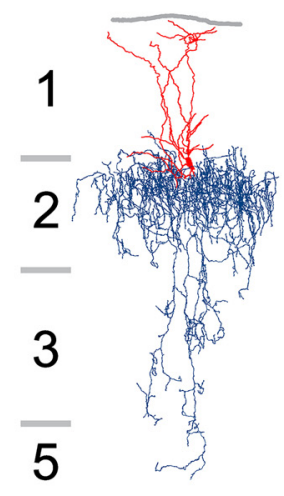

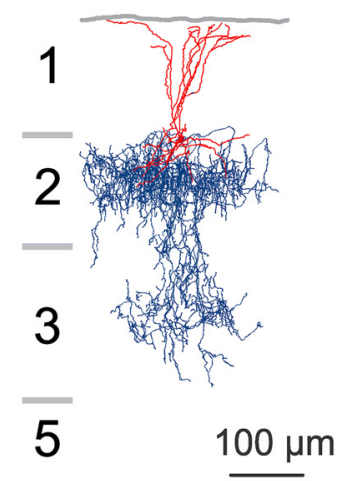

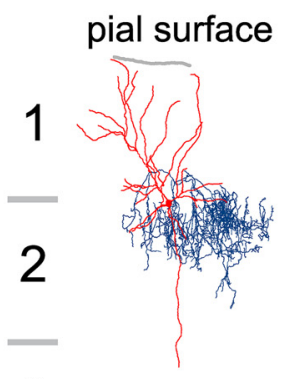

3

axon dendrites
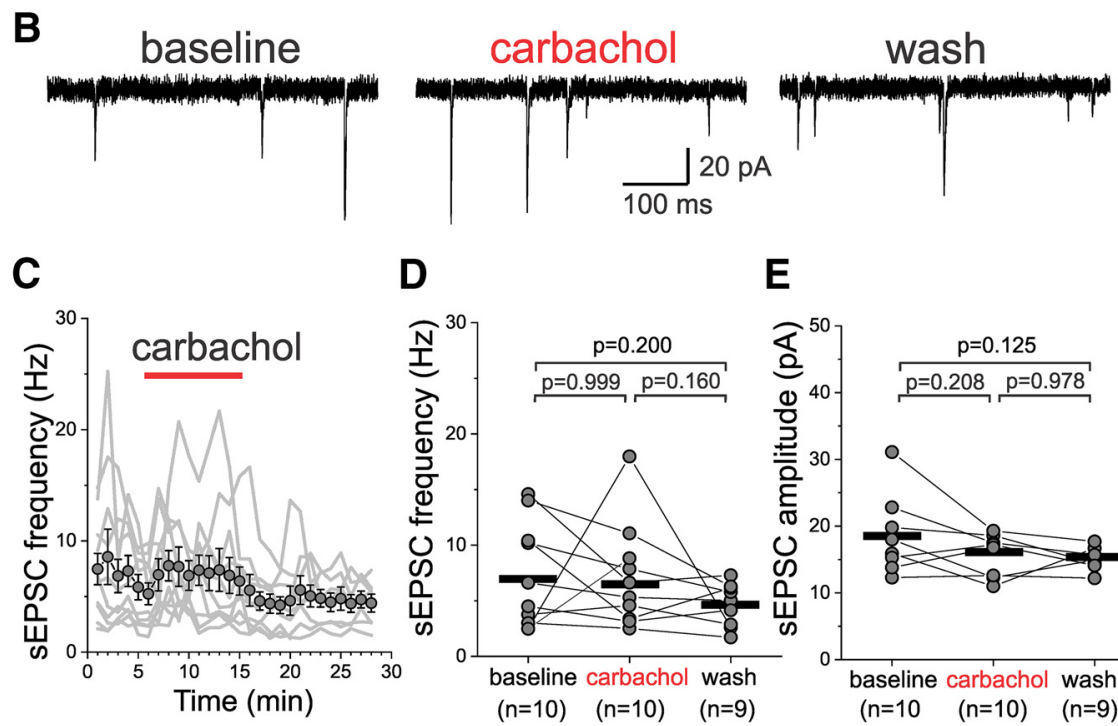

E

Figure 4. Effect of carbachol on sEPSCs recorded from layer $2 \mathrm{PV}^{+}$ChCs with soma near the border with layer 1. A, Examples of the morphology of ChCs with soma near the border with layer 1 . The dendritic tree is shown in red and the axonal arbor in blue. Note that ChC dendrites mostly project onto layer 1 and that the distal tips of the dendrites end near the pial surface. $\boldsymbol{B}$, Examples of sEPSCs recorded from a L2 ChC before (baseline), during $20 \mu \mathrm{M}$ carbachol application (carbachol), and after washout (wash). $\boldsymbol{C}$, Time-course plot illustrating the effects of a 10 min application of $20 \mu \mathrm{M}$ carbachol on sEPSC frequency in ChCs. The gray lines show the data for individual ChCs. The symbols show mean \pm SEM, $n=10$. The sEPSC frequency was measured in $20 \mathrm{~s}$ time windows every $60 \mathrm{~s}$. $\boldsymbol{D}$, Carbachol did not have significant effects on sEPSC frequency when estimated $20 \mathrm{~s}$ before carbachol application (baseline), the last $20 \mathrm{~s}$ before beginning of washout, and after $\geq 10$ min of washout; one-way RM mixed model ANOVA, $F_{(2,19.5)}=2.53, p=0.106$; shown in figure are the results of Sidak-corrected, post hoc pairwise comparisons). The black horizontal bars indicate the mean value for each sample. $\boldsymbol{E}$, Carbachol did not have significant effects on SEPSC amplitude when estimated $20 \mathrm{~s}$ before carbachol application (baseline), the last $20 \mathrm{~s}$ before beginning of washout, and after $\geq 10 \mathrm{~min}$ of washout (one-way RM mixed model ANOVA, $F_{(2,15.4)}=2.89, p=0.086$; shown in figure are the results of Sidak-corrected, post hoc pairwise comparisons). The black horizontal bars indicate the mean value for each sample.

(mean \pm SEM, $n=7$, range: $0-8 \%$ ) of the L3-6 BC dendrites was found at distances $\leq 300 \mu \mathrm{m}$ from the pia, a significantly smaller percentage $\left(\chi^{2}=12.655, p=\right.$ 0.00179 , Kruskal-Wallis ANOVA). These data therefore show that L3-6 BC dendrites integrate excitatory inputs at laminar locations that are largely non-overlapping with those of either L2 BC or L2 ChC dendrites, suggesting a morphologic correlate of the different carbachol effects on excitatory input. On the other hand, quantitative analysis showed that the axons of L3-6 BCs (Fig. 5D), projected into both deep and superficial layers in a multipolar fashion, as observed for L2 BC dendrites, albeit with greater projection length (Fig. 5E). Across cortical layers, the L3-6 BC axons projected in an approximately bimodal manner, with a tendency for a denser projection to the superficial layers (Fig. $5 F$ ), although the peak axonal length did not differ significantly $(t=0.355, p=0.728, n=$ 7; Shapiro-Wilk, raw data $p=0.00127$, $\log$ data $p=$ $0.9959)$ between superficial layers (peak length, mean \pm SEM: $383 \pm 183 \mu \mathrm{m}$ ) and deep layers (peak length, mean \pm SEM: $212 \pm 82 \mu \mathrm{m})$. The percentage of L3-6 BC axonal arbor length found at a distance $\leq 300 \mu \mathrm{m}$ from the pial surface was small (mean \pm SEM, $1.7 \pm 0.4 \%$, range: $0-6.25 \%)$, suggesting that the laminar distribution of the L3-6 BC axons is similar to that of L3-6 BC dendrites. Hence, these data show that L3-6 BCs with carbachol- 
A L3-6 BC
dendrites

L2 BC

L2 ChC dendrites dendrites

D L3-6 BC axons
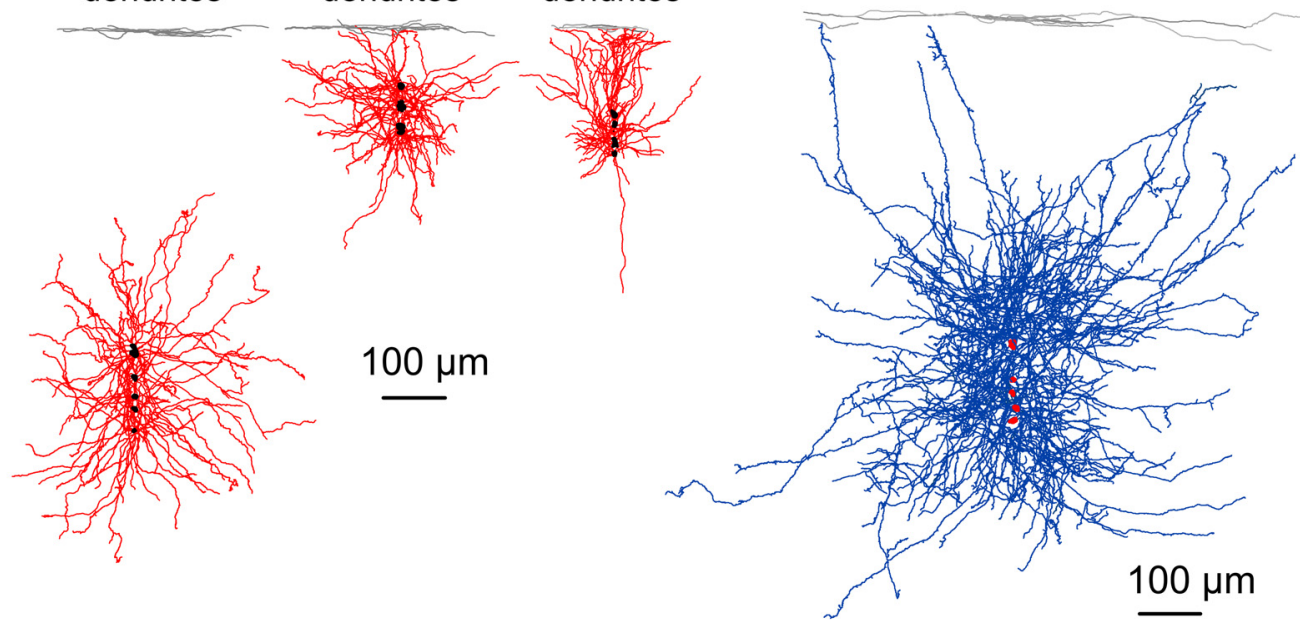

B

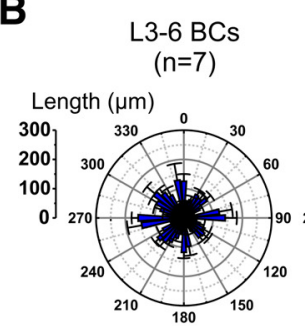

C

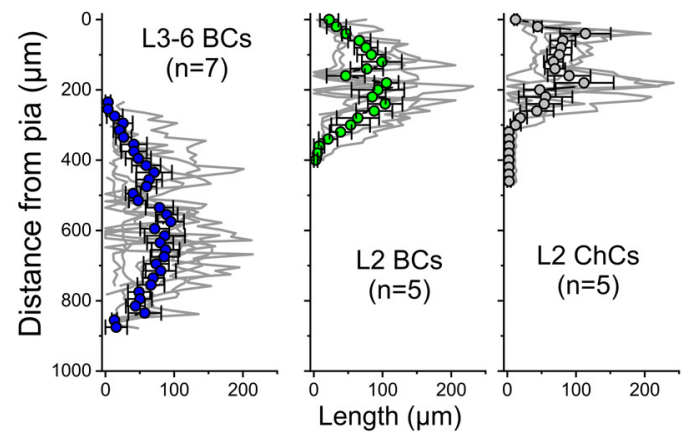

E $(n=5)$

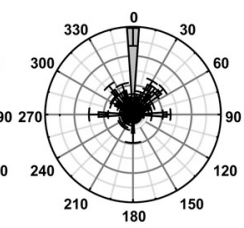

F
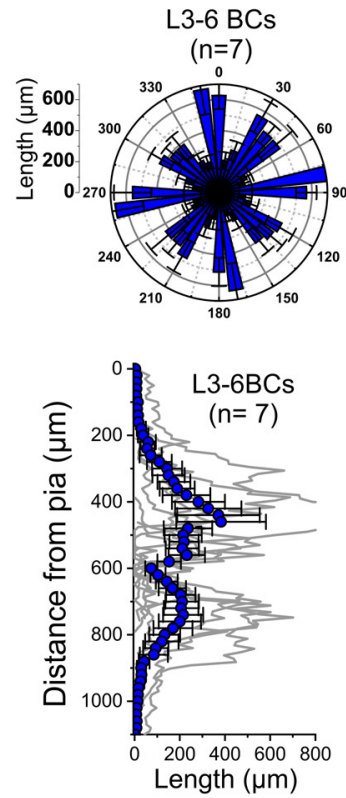

Figure 5. Quantitative morphometric analysis of $\mathrm{PV}^{+}$neuron dendritic trees and axonal arbors. $\boldsymbol{A}$, Reconstructions of the dendritic tree of individual $\mathrm{PV}^{+}$cells are shown superimposed and aligned, in the $y$-axis, relative to the pial surface and centered, in the $x$-axis, by the cell body. The somata are indicated in black. $\boldsymbol{B}$, Polar histograms of the distribution of the $\mathrm{PV}^{+}$neuron dendrite length, relative to the soma. $\boldsymbol{C}$, Distribution of the $\mathrm{PV}^{+}$neuron dendrite length, as a function of distance from the pial surface. The symbols show mean \pm SEM. $\boldsymbol{D}$, Reconstructions of the axonal arbor of individual PV ${ }^{+}$L3-6 BCs are shown superimposed and aligned, in the $y$-axis, relative to the pial surface and centered, in the $x$-axis, by the cell body. The somata are indicated in red. $\boldsymbol{E}$, Polar histogram of the distribution of the $\mathrm{PV}^{+}$L3-6 BC axon length, relative to the soma. $\boldsymbol{F}$, Distribution of the PV ${ }^{+}$L3-6 BC axon length, as a function of distance from the pial surface. The symbols show mean \pm SEM.

stimulated excitatory drive project axonal output mainly within layers 3-6, with weak output onto layer 2.

The $\mathrm{PV}^{+}$neurons from which we recorded sEPSCs were located throughout the IL, PL, and AC cytoarchitectonic areas of the mouse medial PFC. Thus, one possibility is that the different effect of carbachol on SEPSCs recorded from L3-6 BCs versus $L 2$ BCs or L2 ChCs was due to a different areal localization of the L3-6 BCs versus the other $\mathrm{PV}^{+}$neuron subtypes. To examine this idea, we determined the location by cytoarchitectonic area of the $\mathrm{PV}^{+}$neurons tested with carbachol (Fig. 6A). For each
$\mathrm{PV}^{+}$cell we estimated the sEPSC frequency during the effects of carbachol as a percentage of the baseline value. Next, to compare the effect of carbachol on sEPSCs, we performed two-way ANOVA with cell type and cytoarchitectonic area as main factors (Fig. 6B). We found that cell type had a significant effect $\left(F_{(2,17)}=7.647, p=0.00428\right)$, driven by the marked SEPSC potentiation in L3-6 BCs (Fig. 6B). However, the effect of cytoarchitectonic area (Fig. 6C) was not significant $\left(F_{(2,17)}=1.101, p=0.355\right)$ and there was no significant interaction $\left(F_{(4,17)}=0.191\right.$, $p=0.939)$. These data suggest that, compared with $L 2$ 


\section{A}
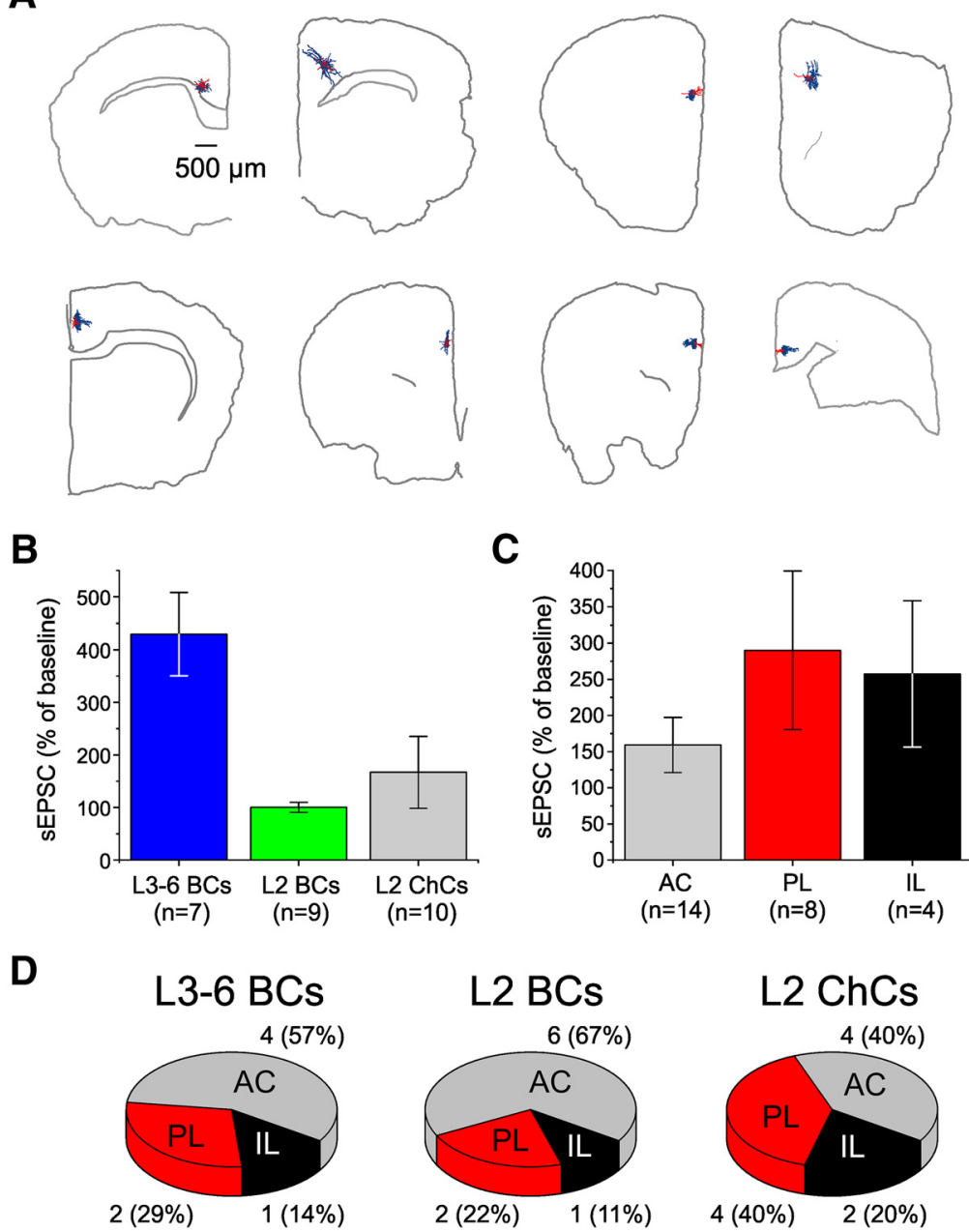

Figure 6. Distribution of the $\mathrm{PV}^{+}$neurons tested for the effect of carbachol on sEPSCs, across cytoarchitectonic areas of the mouse PFC. $\boldsymbol{A}$, Examples illustrating the location of recorded $\mathrm{PV}^{+}$neurons in different PFC slices. Shown are $\mathrm{PV}^{+}$neurons for which we reconstructed the dendritic tree (red) and axonal arbors (blue), with the contour of each brain slice, and some landmarks indicating location of white matter tracks. Neurons were localized to the IL, PL, or AC cortex areas using the Allen Institute Mouse Brain Atlas (http://mouse.brain-map.org/static/atlas). B, Potentiation by carbachol of the sEPSCs recorded from L3-6 BCs, L2 BCs and L2 ChCs. Data are from the experiments reported in Figures 2-4 after each neuron was located in the IL, PL, or AC areas. $\boldsymbol{C}$, Potentiation by carbachol of the sEPSCs recorded from $\mathrm{PV}^{+}$neurons located in the AC, PL, or IL cortices. Two-way ANOVA of the data in parts $\boldsymbol{B}$, $\boldsymbol{C}$ performed using cell type and cytoarchitectonic area as the main factors showed a significant effect of cell type $\left(F_{(2,17)}=7.647\right.$, $p=0.00428)$, whereas there was no significant effect of cytoarchitectonic area $\left(F_{(2,17)}=1.233, p=0.316\right)$ and no significant interaction $\left(F_{(4,17)}=0.099, p=0.981\right)$. $D$, Charts illustrating the distribution of recorded L3-6 BCs, L2 BCs, and L2 ChCs across the three cytoarchitectonic areas of the mouse medial PFC.

BCs or L2 ChCs, the L3-6 BCs with sEPSC potentiation by carbachol were not differentially localized by cytoarchitectonic area. An analysis of the anatomic distribution of the recorded neurons showed that most cells were localized in the AC cortex, and a minority of cells were in the IL cortex (Fig. 6D). However, we found no clear evidence of a bias in the area distribution of L3-6 BCs relative to L2 BCs or L2 ChCs (Fig. 6D). Because our anatomic analysis was limited by the small sample of neurons, we cannot rule out that in a larger sample we may detect significant differences in the effect of carbachol between cytoarchitectonic areas. However, since carbachol had a robust effect on sEPSCs on L3-6 BCs relative to L2 BCs and L2 ChCs that was independent of areal localization, our data indicate that the effect of cell type is stronger than any potential differences between PFC areas.

The increase in excitatory drive in L3-6 BCs may reflect AChR-mediated stimulation of PN firing, since previous studies showed that carbachol stimulates PN activity. In this case, the effects of carbachol on L3-6 BC sEPSCs should be prevented by the voltage-dependent $\mathrm{Na}^{+}$channel blocker tetrodotoxin, which inhibits action potential firing. Alternatively, it is possible that carbachol increases the probability of action potential-independent glutamate release at excitatory synapses onto L3-6 BCs, an effect that would be observed after tetrodotoxin application. To distinguish between these two possibilities, we tested the effects of carbachol $(20 \mu \mathrm{M})$ applied in the presence of 
A

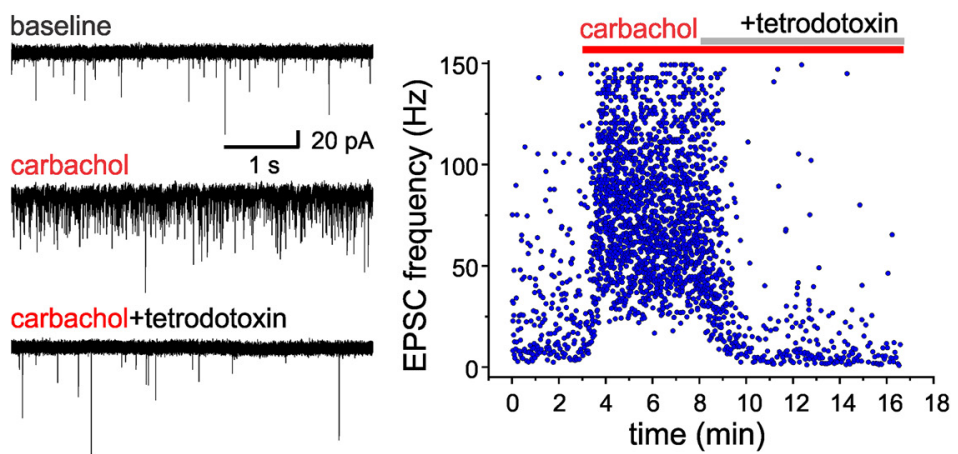

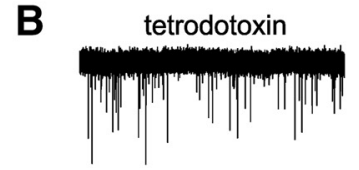

C

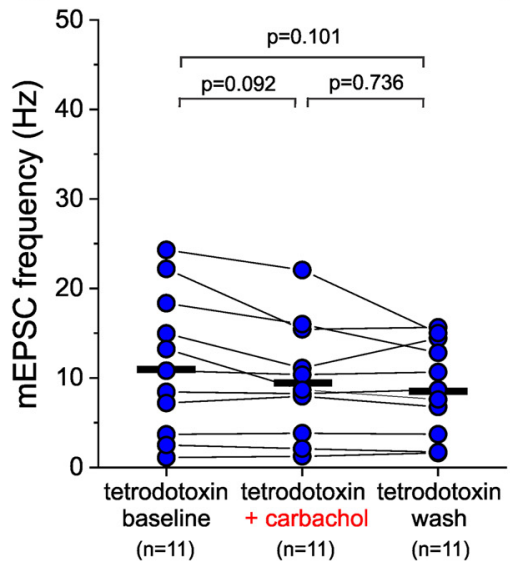

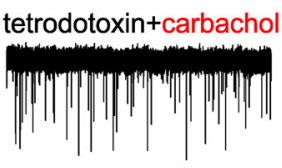

tetrodotoxin

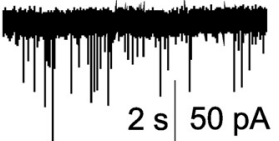

D

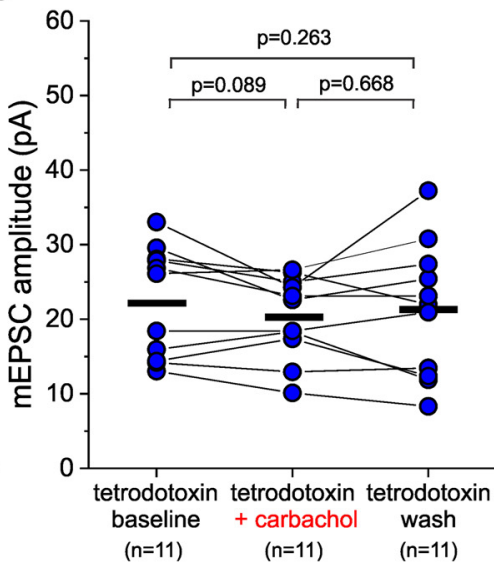

Figure 7. The voltage-dependent $\mathrm{Na}^{+}$channel blocker tetrodotoxin prevents the carbachol-induced potentiation of sEPSCs recorded from L3-6 PV ${ }^{+}$BCs. A, left panel, sEPSCs recorded from a L3-6 BC during baseline, after addition of carbachol (20 $\mu$ M) and after addition of tetrodotoxin $(1 \mu \mathrm{M})$. Right panel, Time-course plot illustrating the effects of carbachol and tetrodotoxin addition on the instantaneous EPSC frequency (estimated as the inverse of the inter-event interval) for the EPSCs in the experiment in the left panel. $\boldsymbol{B}, \mathrm{mEPSC}$ recorded in the continuous presence of tetrodotoxin $(1 \mu \mathrm{M})$ before and after the addition of $20 \mu \mathrm{M}$ carbachol. $\boldsymbol{C}$, Carbachol applied in the continuous presence of tetrodotoxin did not increase the mEPSC frequency, while producing a small but significant decrease when estimated $20 \mathrm{~s}$ before carbachol application (tetrodotoxin baseline), $20 \mathrm{~s}$ before beginning of washout (tetrodotoxin + carbachol), and after $\geq 10$ min of washout (tetrodotoxin wash; one-way RM ANOVA $F_{(2,16)}=4.634, p=0.022 ;$ shown in the figure are the $p$ value results of Sidak-corrected, post hoc pairwise comparisons). The black horizontal bars indicate the mean value for each sample. $\boldsymbol{D}$, Carbachol applied in the continuous presence of tetrodotoxin did not have significant effects on mEPSC amplitude when estimated $20 \mathrm{~s}$ before carbachol application (tetrodotoxin baseline), $20 \mathrm{~s}$ before beginning of washout (tetrodotoxin + carbachol), and after $\geq 10$ min of washout (tetrodotoxin wash; one-way RM ANOVA $F_{(2,16)}=1.281, p=0.299$; shown in the figure are the $p$ value results of Sidak-corrected, post hoc pairwise comparisons). The black horizontal bars indicate the mean value for each sample.

tetrodotoxin $(1 \mu \mathrm{M})$. We found that the carbachol-induced increase in SEPSC frequency and amplitude in L3-6 BCs was reversed by the addition of tetrodotoxin (Fig. 7A). Moreover, when carbachol was applied in the continuous presence of tetrodotoxin (Fig. $7 B$ ), neither the miniature EPSC frequency (Fig. 7C) nor amplitude (Fig. 7D), showed significant increases by carbachol (one-way RM ANOVA, mEPSC frequency: $F_{(2,20)}=4.634, p=0.022$; mEPSC amplitude: $\left.F_{(2,20)}=1.281, p=0.299\right)$. These data are consistent with the idea that the effects of carbachol on sEPSCs involve stimulation of PN firing.
In deep cortical layers, PNs express muscarinic and nicotinic AChRs (Obermayer et al., 2017; Radnikow and Feldmeyer, 2018), both of which can be activated by carbachol. However, carbachol stimulation of PN firing in PFC is dependent on mAChR activation (Gulledge et al., 2007; Gulledge et al., 2009; Pafundo et al., 2013). Thus, to determine whether the increase in SEPSC frequency and amplitude by carbachol is consistent with $\mathrm{mAChR}$ stimulation of PN firing, we examined the effects of carbachol on SEPSCs recorded from L3-6 BCs in the presence of the $\mathrm{mAChR}$ antagonist atropine. We first tested whether 

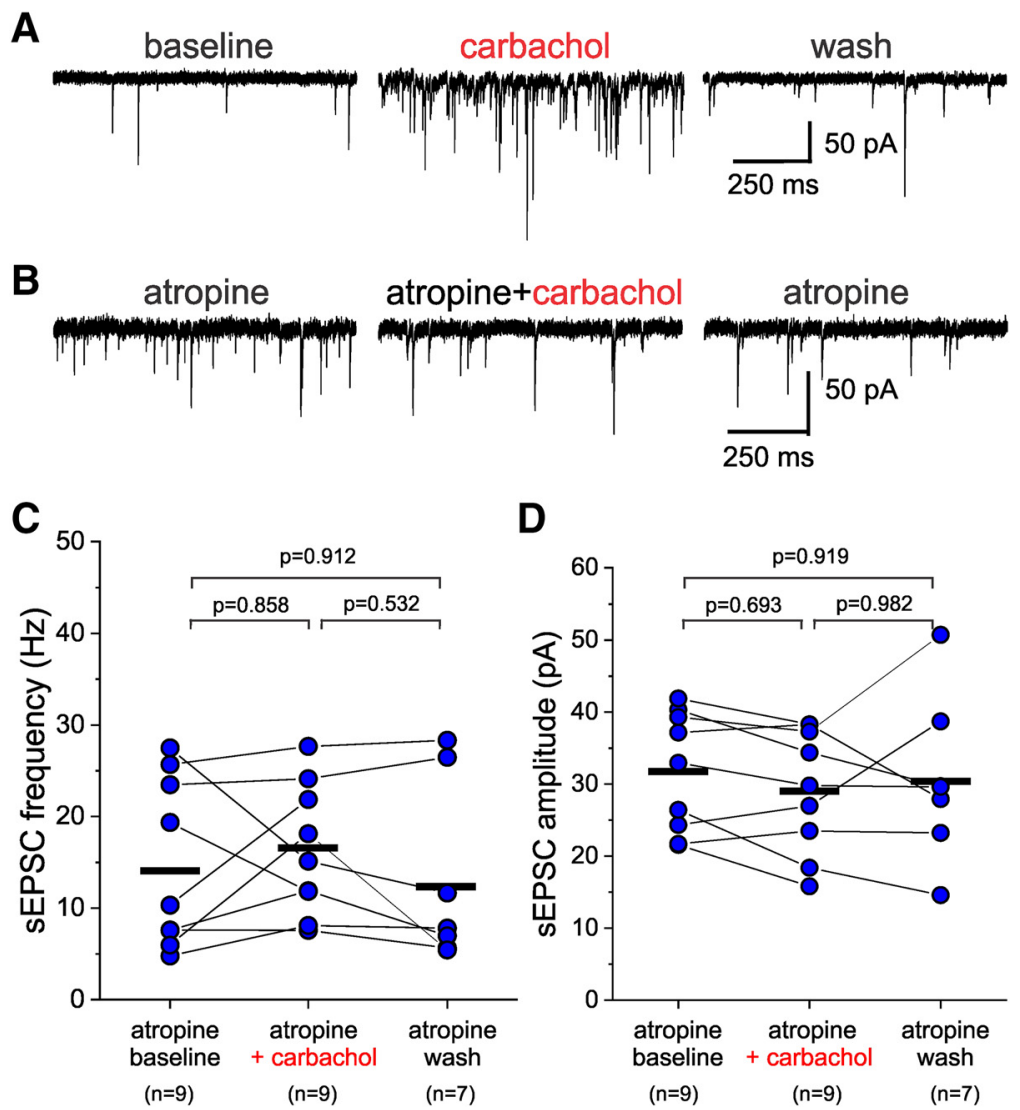

Figure 8. The non-selective mAChR antagonist atropine prevents the effects of carbachol on sEPSCs recorded from L3-6 PV ${ }^{+}$BCs. $\boldsymbol{A}$, Examples of SEPSCs recorded in the continuous presence of the vehicle ethanol $(0.1 \% \mathrm{~V} / \mathrm{V})$ from a layer 5 BC before (atropine baseline), during application of $20 \mu \mathrm{M}$ carbachol (carbachol), and after washout (atropine wash). B, Examples of sEPSCs recorded from a layer $5 \mathrm{BC}$ in the continuous presence of the vehicle ethanol $(0.1 \% \mathrm{~V} / \mathrm{V})$ and atropine (10 $\mu \mathrm{M})$ before (baseline), during application of $20 \mu \mathrm{M}$ carbachol (atropine+carbachol), and after washout (atropine wash). $\boldsymbol{C}$, Carbachol applied in the presence of atropine did not have significant effects on sEPSC frequency when estimated $20 \mathrm{~s}$ before carbachol application (atropine baseline), $20 \mathrm{~s}$ before beginning of washout (atropine+carbachol), and after $\geq 10$ min of washout (atropine wash; one-way RM mixed model ANOVA, $F_{(2,16.46)}=0.813, p=0.461$; shown in figure are the results of Sidak-corrected, post hoc pairwise comparisons). The black horizontal bars indicate the mean value for each sample. $\boldsymbol{D}$, Carbachol applied in the presence of atropine did not have significant effects on sEPSC amplitude when estimated $20 \mathrm{~s}$ before carbachol application (atropine baseline), $20 \mathrm{~s}$ before beginning of washout (atropine + carbachol), and after $\geq 10$ min of washout (atropine wash; one-way RM mixed model ANOVA, $F_{(2,16.11)}=0.524, p=0.602$; shown in figure are the results of Sidak-corrected, post hoc pairwise comparisons). The black horizontal bars indicate the mean value for each sample.

the effects of carbachol are modified by the presence of ethanol, which we used as the vehicle for atropine. We found that in the continuous presence of ethanol at vehicle concentrations $(0.1 \% \mathrm{v} / \mathrm{v})$, carbachol produced a marked increase in the sEPSC frequency and amplitude in deep layer BCs, comparable to that observed in the absence of ethanol (Fig. 8A). In contrast, in the presence of atropine $(10 \mu \mathrm{M})$, carbachol $(20 \mu \mathrm{M})$ application did not alter the SEPSCs recorded from L3-6 BCs (Fig. 8B), and neither sEPSC frequency (Fig. $8 C$ ) nor sEPSC amplitude (Fig. $8 D$ ) were changed significantly (one-way RM mixed model ANOVA, sEPSC frequency: $F_{(2,16.46)}=0.813, p=$ 0.461 , sEPSC amplitude: $\left.F_{(2,16.11)}=0.524, p=0.602\right)$. We additionally used the M1-selective mAChR antagonist pirenzepine (Gulledge and Stuart, 2005; Carr and Surmeier, 2007), since in previous studies the modulation of PFC PN firing by mAChR activation was abolished by M1 subtype $\mathrm{mAChR}$ antagonists or genetic ablation of the M1
mAChR (Gulledge and Stuart, 2005; Carr and Surmeier, 2007; Gulledge et al., 2007, 2009). The carbachol (20 $\mu \mathrm{M})$-induced increase in SEPSC frequency and amplitude in L3-6 BCs was reversed by the addition of pirenzepine (1 $\mu \mathrm{M}$; Fig. 9A). Moreover, when carbachol $(20 \mu \mathrm{M})$ was applied in the continuous presence of $1 \mu \mathrm{M}$ pirenzepine (Fig. 9B), the increases in both sEPSC frequency (Fig. 9C) and SEPSC amplitude (Fig. 9D) were abolished [sEPSC frequency: $F_{(2,27.3)}=0.565, p=0.575$, one-way $\mathrm{RM}$ mixed model ANOVA (on ranks); sEPSC amplitude: $F_{(2,27.4)}=0.009, p=0.991$, one-way $\mathrm{RM}$ mixed model ANOVA (on ranks)]. These data show that the effects of carbachol on sEPSCs recorded from L3-6 BCs are mediated by $\mathrm{M} 1 \mathrm{mAChRs}$.

Our findings that carbachol increases the excitatory drive on L3-6 BCs suggest that carbachol initiates action potential firing in PNs, some of which are a source of excitatory synaptic input onto the L3-6 BCs. Previous 

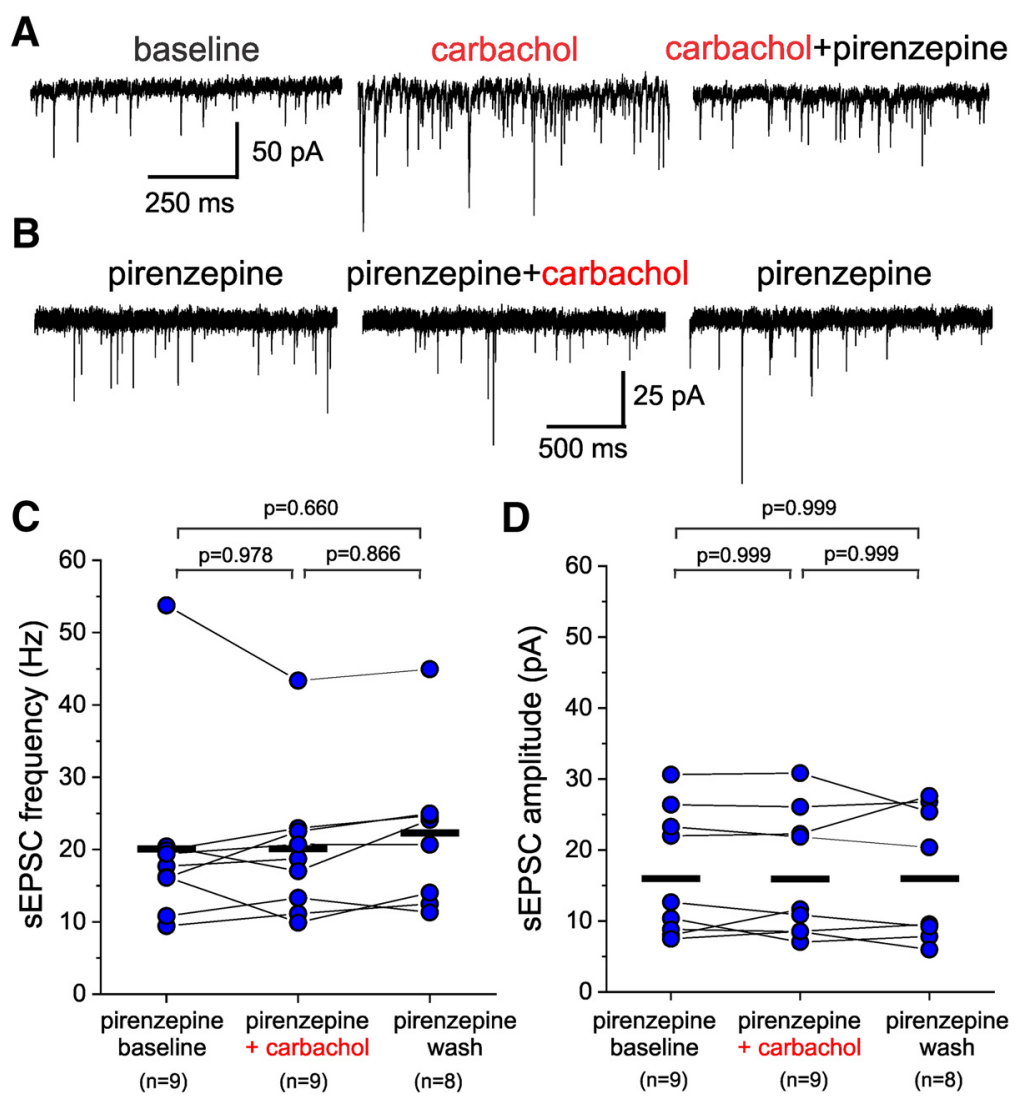

Figure 9. The M1 subtype-selective mAChR antagonist pirenzepine prevents the effects of carbachol on sEPSCs recorded from L3-6 $\mathrm{PV}^{+}$BCs. A, Examples of sEPSCs recorded at baseline (baseline), during application of $20 \mu \mathrm{M}$ carbachol (carbachol), and after addition of $1 \mu \mathrm{M}$ pirenzepine (carbachol+pirenzepine). B. Examples of sEPSCs recorded from a layer 3-6 BC in the continuous presence of pirenzepine (pirenzepine), after addition of carbachol (carbachol+pirenzepine), and after carbachol washout (pirenzepine). $\boldsymbol{C}$, Carbachol applied in the presence of pirenzepine did not have significant effects on sEPSC frequency when estimated $20 \mathrm{~s}$ before carbachol application (pirenzepine baseline), $20 \mathrm{~s}$ before beginning of washout (pirenzepine + carbachol), and after $\geq 10$ min of carbachol washout (pirenzepine wash; one-way RM ANOVA mixed model, $F_{(2,27.3)}=0.517, p=0.575$; shown in figure are the results of Sidak-corrected, post hoc pairwise comparisons). The black horizontal bars indicate the mean value for each sample. $\boldsymbol{D}$, Carbachol applied in the presence of pirenzepine did not have significant effects on sEPSC amplitude when estimated $20 \mathrm{~s}$ before carbachol application (pirenzepine baseline), $20 \mathrm{~s}$ before beginning of washout (pirenzepine + carbachol), and after $\geq 10$ min of carbachol washout (pirenzepine wash; one-way RM ANOVA mixed model, $F_{(2.27 .4)}=0.009, p=0.991$; shown in figure are the results of Sidak-corrected, post hoc pairwise comparisons). The black horizontal bars indicate the mean value for each sample.

findings suggest that mAChR-mediated stimulation of action potential firing by carbachol is more pronounced in PNs from deep layers (Dembrow et al., 2010; Joshi et al., 2016; Baker et al., 2018). Our data in Figure 5 also show that the dendrites of L3-6 BCs integrate excitatory input mainly in deep layers, in contrast with the dendrites of $L 2$ $\mathrm{PV}^{+}$cells, which receive input in layers 1 and 2 . Thus, we obtained current clamp recordings from $\mathrm{PNs}$ in deep layer 3 and layer 5 (L3-5 PNs; Fig. 10A), in the continuous presence of glutamate and $\mathrm{GABA}_{\mathrm{A}}$ receptor antagonists, to assess if carbachol initiates action potential firing in L3-5 PNs. We additionally applied depolarizing current steps to evoke spiking, assessing changes in the response to excitatory currents. The response to depolarizing current steps during baseline before carbachol application showed that the recorded L3-5 PNs $(n=7)$ had either regular spiking $(n=5)$ or bursting properties $(n=2)$ typical of PNs (Fig. 10B,D). After monitoring the resting membrane potential and the response to depolar- izing current steps (Fig. 10B) for at least 3 min of baseline recordings, we bath-applied carbachol $(20 \mu \mathrm{M})$ for $5 \mathrm{~min}$. Carbachol depolarized the L3-5 PN membrane potential, reaching action potential threshold and eliciting firing independent of current injection in 6 of 7 recorded L3-5 PNs (Fig. 10B). As expected, the membrane depolarization enhanced the response to the depolarizing current steps (Fig. 10B), and this effect was reversed or partly reversed by injection of constant hyperpolarizing current (data not shown). By 2 min of carbachol application, the depolarization developed significant values (membrane potential, mean \pm SEM, baseline: $-71 \pm 2 \mathrm{mV}$, carbachol: $-52 \pm 5$ $\mathrm{mV}, n=7, t_{(6)}=5.04, p=0.0023$, paired sample Student's $t$ test), and rapidly reached suprathreshold levels. Figure $10 \mathrm{C}$ shows the time course of the carbacholinduced PN depolarization and the frequency of spikes evoked by this depolarization, both measured in a time window just before the injected current steps, as indicated in Figure 10B. The carbachol-induced depolariza- 
A

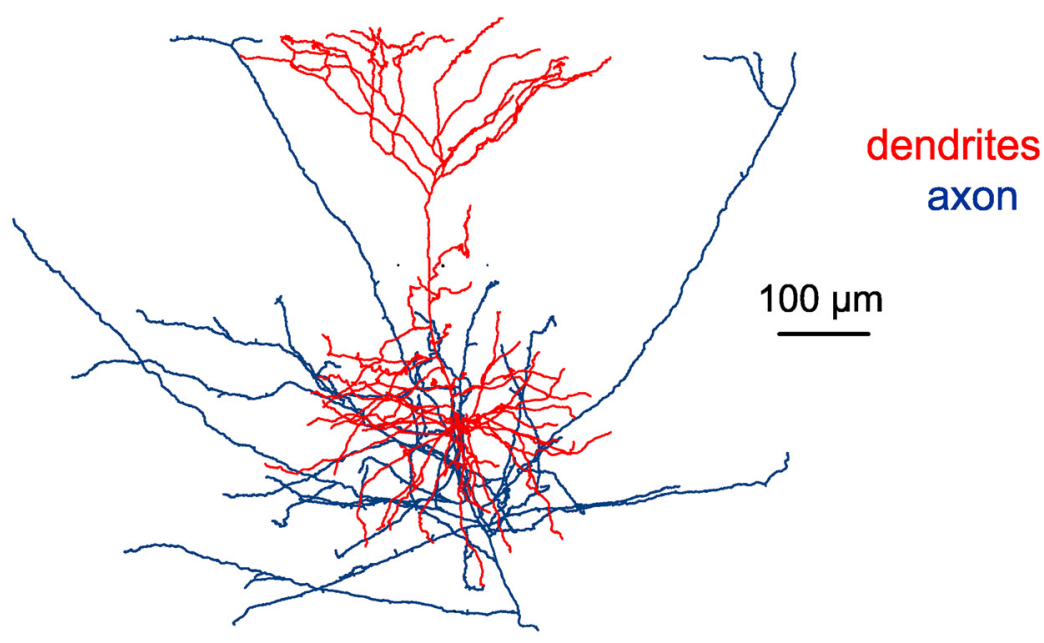

B baseline
(CNQX+GBZ)

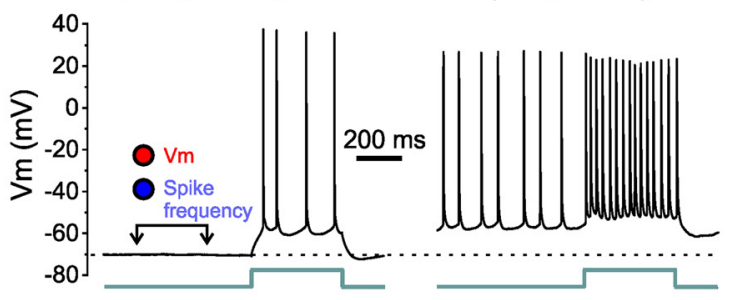

D

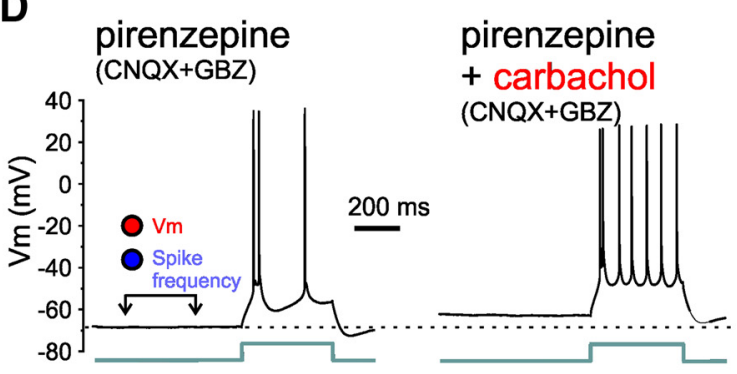

C

(CNQX+GBZ)

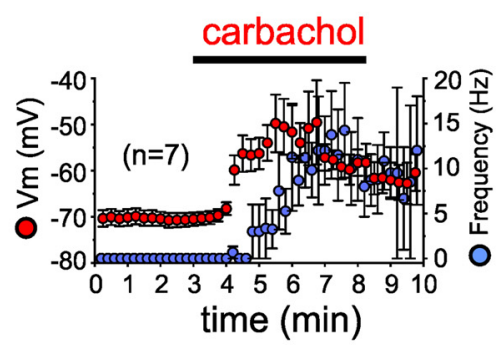

E

$(\mathrm{CNQX}+\mathrm{GBZ})$

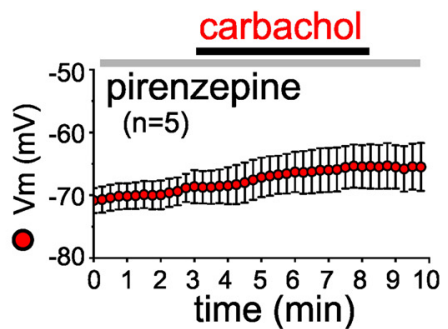

Figure 10. Effects of carbachol on the membrane potential and excitability of L3-6 PNs, tested in the presence of synaptic receptor blockers (CNQX and gabazine). $\boldsymbol{A}$, Reconstruction of the dendritic tree of a layer 5 PN for which the effects of carbachol were assessed during current clamp recordings. $\boldsymbol{B}$, Examples of membrane potential $(\mathrm{Vm})$ recorded from a layer $5 \mathrm{PN}$ before (baseline) and during application of $20 \mu \mathrm{M}$ carbachol (carbachol), in the presence of synaptic receptor blockers CNQX and gabazine (GBZ). The time window for measurements of $\mathrm{Vm}$ (minimum value within the window) and of spike frequency (independent of injection of current steps) is illustrated in the baseline recording example. The injected current step had identical amplitude (70 pA) in baseline and carbachol conditions. Note that during the depolarization induced by carbachol, action potential amplitude was typically reduced. $\boldsymbol{C}$, Plot illustrating the time course of changes in $\mathrm{Vm}$ (red) and in spike frequency (blue) measured during the time window indicated in $\boldsymbol{B}$. Carbachol depolarized the membrane potential significantly by $2 \mathrm{~min}$ of carbachol application (baseline: $-71 \pm 2 \mathrm{mV}$, carbachol: $-52 \pm 5 \mathrm{mV}, n=7, t_{(6)}=5.04, p=0.0023$, paired $t$ test). Note that for several PNs the strong depolarization by carbachol produced depolarization block of action potential firing, which was prevented by hyperpolarizing current injection (see text in Results). Measurements obtained during hyperpolarizing current injection were not included in this time-course plot. $\boldsymbol{D}$, Examples of Vm recordings from a layer $5 \mathrm{PN}$ in the continuous presence of the M1 mAChR antagonist pirenzepine (1 $\mu \mathrm{M})$ before (pirenzepine) and during application of $20 \mu \mathrm{M}$ carbachol (pirenzepine+carbachol). Vm and spike frequency measurements were performed as indicated in $\boldsymbol{C}$. The injected current step had identical amplitude $(80 \mathrm{pA})$ in baseline and carbachol conditions. Note that in the presence of pirenzepine, the carbachol-induced depolarization was subthreshold and did not evoke spikes independent of the injected current steps. $\boldsymbol{E}$, Plot illustrating the time course of changes in $\mathrm{Vm}$. In the presence of pirenzepine, carbachol depolarized the membrane potential, but the depolarization was small and remained below action potential threshold. The depolarization was not significant by $2 \mathrm{~min}$ of application but peaked at significant levels by $5 \mathrm{~min}$ (baseline: $-69 \pm 2 \mathrm{mV}, 2 \mathrm{~min}$ pirenzepine + carbachol: $-67 \pm 3 \mathrm{mV}$. 5 min pirenzepine+carbachol: $-65 \pm 3 \mathrm{mV}, n=5, F_{(2,8)}=8.555, p=0.0103$, one-way RM ANOVA; baseline vs 2 min: $p=0.239$, baseline vs 5 min: $p=0.0034$, Dunnett's post hoc tests). 
tion directly produced action potentials at a frequency of up to $15 \mathrm{~Hz}$ independent of the response to the injected current steps (Fig. 10C). The depolarization and action potential firing evoked by carbachol were reversed with drug washout in two of seven L3-5 PNs, but in most cells, the carbachol effects were persistent and did not reverse completely after up to 20 min of wash (data not shown). In four of seven recorded L3-5 PNs, within 2 min of eliciting spiking carbachol produced depolarization block of the action potentials, which was readily reversed by hyperpolarizing current injection (data not shown).

We next tested whether the M1-selective mAChR antagonist pirenzepine reduced the action potential firing elicited in L3-5 PNs by carbachol, as expected if the effect of carbachol contributes to the increase of excitatory drive onto L3-6 BCs (Figs. 2, 9). In recordings from L3-5 PNs ( $n=5$, regular spiking $n=4$, bursting $n=1$ ), in the presence of pirenzepine $(1 \mu \mathrm{M})$, carbachol $(20 \mu \mathrm{M})$ did not depolarize the cells or produced a small depolarization that did not directly elicit action potential firing in any of the five L3-5 PNs tested (Fig. 10D). By 2 min of carbachol application in the presence of pirenzepine, the depolarization was not significant (Fig. 10E), but it peaked at significant levels by 5 min (membrane potential, mean \pm SEM, pirenzepine baseline: $-69 \pm 2 \mathrm{mV}$, 2-min pirenzepine+carbachol: $-67 \pm 3 \mathrm{mV}$, 5-min pirenzepine+ carbachol: $-65 \pm 3 \mathrm{mV} . n=5, F_{(2,8)}=8.555, p=0.0103$, one-way RM ANOVA, Sidak post hoc tests, baseline vs 2 min: $p=0.372$, baseline vs 5 min: $p=0.010)$. In the presence of pirenzepine, carbachol did not initiate PN spikes independent of the injected current steps, therefore these experiments did not produce spike frequency measures (Fig. 10E). Our current clamp recordings thus showed that carbachol produces a suprathreshold depolarization that elicits L3-5 PN firing via activation of $\mathrm{M} 1$ mAChRs.

$\mathrm{mAChR}$ expression is significant in $\mathrm{PNs}$ and also in $\mathrm{PV}^{+}$ neurons (Paul et al., 2017; Oda et al., 2018), and mAChR stimulation increases the intrinsic excitability of $\mathrm{PV}^{+}$neurons in PFC (Pafundo et al., 2013; Yi et al., 2014). Hence, our data showing increased excitatory input onto $\mathrm{PV}^{+}$ L3-6 BCs, and previous findings of increased L3-6 BC intrinsic excitability, suggest that $m A C h R$ activation has overall excitatory effects on $\mathrm{PV}^{+} \mathrm{BCs}$ in layers 3-6. However, previous studies assessing the effects of AChR stimulation on the membrane potential of $\mathrm{PV}^{+}$neurons from the hippocampus or from frontal, somatosensory, or visual cortices reported conflicting results, including a membrane potential hyperpolarization that would have inhibitory effects (Kawaguchi, 1997; Xiang et al., 1998; Yi et al., 2014; Bell et al., 2015; Yi et al., 2015; Wenger Combremont et al., 2016). To determine the effects of carbachol on the membrane potential and intrinsic excitability of $\mathrm{PV}^{+}$neurons in PFC, we obtained current clamp recordings from L3-6 $\mathrm{PV}^{+}$neurons in the continuous presence of glutamate and $\mathrm{GABA}_{\mathrm{A}}$ receptor antagonists. All recorded neurons exhibited fast spiking properties consistent with those of $\mathrm{PV}^{+}$cells (Fig. 11A,C) and had BC morphology (data not shown). Figure $11 A$ shows that carbachol $(20 \mu \mathrm{M})$ applied for 5 min depolarized the mem- brane potential of the L3-6 BCs (Fig. 11B). The carbacholinduced depolarization was small (mean \pm SEM, baseline: $-74 \pm 2 \mathrm{mV}$, carbachol $5 \mathrm{~min}:-69 \pm 3 \mathrm{mV}$ ), but was significant relative to baseline (paired sample Student's $t$ test, $t_{(8)}=2.565, p=0.0333$ ). Contrasting with the strong suprathreshold depolarization of L3-5 PNs, the L3-6 BC depolarization was largely subthreshold, since in most L3-6 BCs (eight of nine) carbachol did not directly elicit firing (Fig. 11A). As expected, the membrane depolarization enhanced the response to depolarizing current steps (Fig. 11A) in all L3-6 BCs, and this effect was reversed or partly reversed by injection of constant hyperpolarizing current (data not shown). However, carbachol did not initiate $\mathrm{PV}^{+}$neuron spikes independent of the injected current steps in most L3-6 BCs (eight of nine), and thus we did not obtain measures of spike frequency (Fig. 11B).

$\mathrm{PV}^{+}$neurons express mAChRs of $\mathrm{M} 1, \mathrm{M} 2$ and $\mathrm{M} 3$ subtypes (Hajos et al., 1998; Paul et al., 2017; Oda et al., 2018), as well as nicotinic AChRs (Muñoz and Rudy, 2014). Thus, to assess whether the depolarization of $\mathrm{PV}^{+}$ cells is mediated by mAChRs, we applied carbachol (20 $\mu \mathrm{M})$ in the continuous presence of the non-selective mAChR antagonist atropine $(10 \mu \mathrm{M})$, in addition to glutamate and $\mathrm{GABA}_{\mathrm{A}}$ receptor antagonists (Fig. 11C). As shown in Figure 11D, the L3-6 BC depolarization was abolished in the presence of atropine (membrane potential, mean \pm SEM, atropine baseline: $-66 \pm 3 \mathrm{mV}$, atropine+ carbachol $5 \mathrm{~min}:-67 \pm 2 \mathrm{mV}$, atropine + carbachol $8 \mathrm{~min}$ : $-67 \pm 4 \mathrm{mV}, n=5$; one-way RM ANOVA, on ranks, $F_{(2,8)}$ $=1.500, p=0.285)$. In the presence of atropine, carbachol did not initiate $\mathrm{PV}^{+}$neuron spikes independent of the injected current steps; therefore, we could not obtain measures of spike frequency in this condition (Fig. 11D). These data show that, via mAChRs, carbachol produces a depolarization of the L3-6 BC membrane potential which, relative to the depolarization of L3-6 PNs, is small and does not initiate action potential firing. Given that CNQX, the antagonist used here to block glutamate synaptic transmission does not inhibit NMDA or metabotropic glutamate receptors, we cannot rule out that these receptors mediate the observed subthreshold depolarization (for additional details, see Discussion).

The results reported in Figure 11, and those of previous studies (Kawaguchi, 1997; Gulledge et al., 2007; Pafundo et al., 2013; Yi et al., 2014), suggest that mAChRs do not directly evoke action potential firing in $\mathrm{PV}^{+}$cells. However, since carbachol increased the excitatory drive (Fig. 2) and produced a subthreshold depolarization (Fig. 11), these effects, combined, could recruit L3-6 BC activity. To test this idea, we performed current clamp recordings from L3-6 BCs with GABA $_{A}$ receptor-mediated inhibition blocked, but glutamate receptor-mediated transmission intact. During 5 min of baseline recording, the L3-6 BCs displayed relatively frequent spontaneous EPSPs (sEPSPs) and stable resting membrane potential values (Fig. 12A). After carbachol (20 $\mu \mathrm{M})$ was applied, most L3-6 BCs (12/13) displayed an increase in the frequency and amplitude of sEPSPs (Fig. 12A), consistent with the potentiation of sEPSCs by carbachol (Fig. 2). In the absence of CNQX, carbachol stimulated the firing of action poten- 

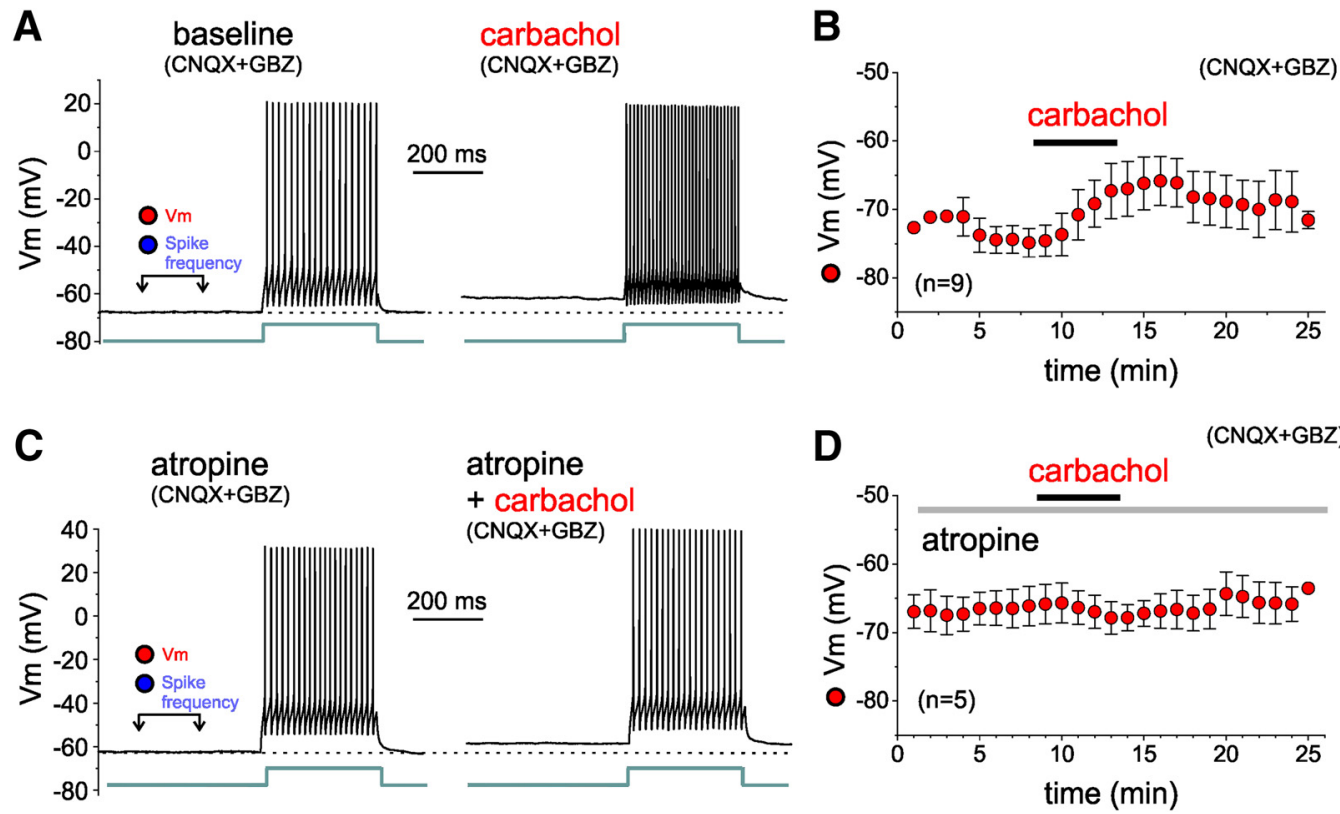

Figure 11. Effects of carbachol on the membrane potential and excitability of L3-6 BCs, tested in the presence of synaptic receptor blockers (CNQX and gabazine). A, Examples of membrane potential $(\mathrm{Vm})$ recorded from a layer 5 BC before (baseline) and during application of $20 \mu \mathrm{M}$ carbachol (carbachol), in the presence of synaptic receptor blockers CNQX and gabazine (GBZ). Measurements of $\mathrm{Vm}$ and of spike frequency were obtained as in Figure 10. The injected current step had identical amplitude ( $80 \mathrm{pA})$ in baseline and carbachol conditions. Note that carbachol application did not elicit action potential firing. $\boldsymbol{B}$, Plot illustrating the time course of changes in $\mathrm{Vm}$ measured during the time window indicated in $\boldsymbol{A}$. Carbachol depolarized the membrane potential significantly by 5 min of application and peaked at $8 \mathrm{~min}$ [baseline: $74 \pm 2 \mathrm{mV}$, carbachol $5 \mathrm{~min}:-69 \pm 3 \mathrm{mV}$, carbachol $8 \mathrm{~min}:-66 \pm 4 \mathrm{mV}, n=9$; one-way RM ANOVA (on ranks), $F_{(1.12,16)}=4.490, p=0.060$, baseline vs $5 \mathrm{~min}: p=0.024$, baseline vs 8 min: $p=0.170$, Sidak-corrected, post hoc pairwise comparisons]. C, Examples of $\mathrm{Vm}$ recordings from a layer $5 \mathrm{BC}$ in the continuous presence of the mAChR antagonist atropine $(10 \mu \mathrm{M})$ before (atropine) and during application of $20 \mu \mathrm{M}$ carbachol (carbachol). Vm measurements were performed as indicated in $\boldsymbol{C}$. The injected current step had identical amplitude (110 pA) in atropine and carbachol conditions. $\boldsymbol{D}$, Plot illustrating the time course of changes in Vm. In the presence of atropine, the depolarization of the L3-6 BC membrane potential was abolished (atropine baseline: $-66 \pm 3 \mathrm{mV}$, atropine+carbachol $5 \mathrm{~min}:-67 \pm 2 \mathrm{mV}$, atropine + carbachol $8 \mathrm{~min}:-67 \pm 4 \mathrm{mV}, n=5$; one-way RM ANOVA, on ranks, $\left.F_{(2,8)}=1.500, p=0.285\right)$.

tial bursts in 11/13 L3-6 BCs (Fig. 12B,C), thus having effects markedly different from those observed with excitatory input blocked. Most L3-6 BCs (7/11) were silent during baseline but displayed bursts of action potentials by $3.1 \pm 0.7 \mathrm{~min}$ of carbachol application. Other cells (4/11) displayed bursts at low frequency during baseline, and the effects of carbachol increased the number of bursts observed. Some action potential bursts were preceded by a long depolarizing ramp simultaneous with a marked increase in the sEPSP number (Fig. 12B, right panel). Other firing bursts were not preceded by a depolarizing ramp or increase in sEPSPs but were initiated after a sharp depolarization (Fig. 12C, right panel). The bursts preceded by a depolarizing ramp were typically associated with a plateau depolarization that eventually inactivated the $\mathrm{Na}^{+}$spikes (Fig. 12B, left panel). In contrast, spike bursts initiated by sharp depolarizations without a ramp usually ended when the membrane potential started a decay to baseline values (Fig. 12C, left panel). The depolarizing ramps may reflect direct input from excitatory cells that progressively increase their activity until driving a burst in the network, whereas episodes without a preceding ramp may reflect bursts propagating in the network after initiation at a distant site. The mechanisms producing these different modes of carbachol-induced bursts of spikes are unclear, but do not seem to depend on unique properties of each cell, because single $\mathrm{PV}^{+}$ cells alternated between these modes of burst spiking. Independent of the underlying mechanisms, all firing episodes, preceded by a depolarizing ramp or not, were dependent on glutamate synaptic transmission since they were eliminated by CNQX (Fig. 12D). These results show that the increase in excitatory synaptic drive by carbachol can evoke action potential firing in L3-6 BCs.

\section{Discussion}

\section{mAChR stimulation increases the excitatory drive onto $\mathrm{PV}^{+}$neurons in a cell type- and layer-specific manner}

To gain insight into the cellular mechanisms by which cholinergic neuromodulation shapes network activity in the PFC, we assessed the effects of AChR activation on $\mathrm{PV}^{+}$neurons. Previous studies of mouse PFC showed that AChR stimulation facilitates PN firing (Dembrow et al., 2010; Obermayer et al., 2017; Baker et al., 2018; Radnikow and Feldmeyer, 2018), an effect that may enhance the excitatory synaptic drive onto $\mathrm{PV}^{+}$cells. Therefore, we characterized the effects of carbachol on excitatory drive by measuring changes in the frequency and amplitude of 
A
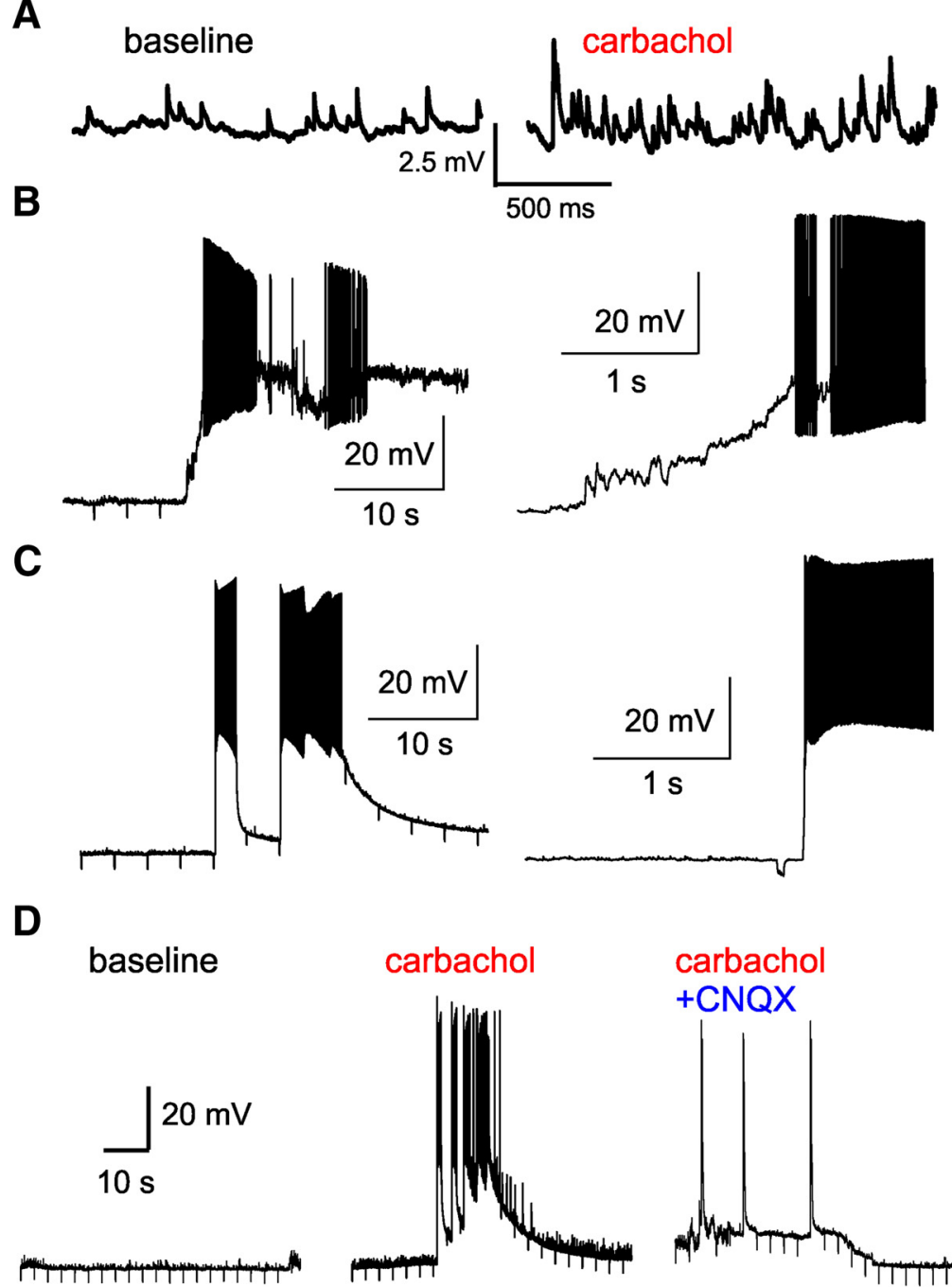

Figure 12. Action potential bursts induced by carbachol in $\mathrm{PV}^{+}$L3-6 BCs in the absence of CNQX. $\boldsymbol{A}$, Examples of sEPSPs recorded from a BC during baseline and after addition of carbachol $(20 \mu \mathrm{M})$ to the bath solution. $\boldsymbol{B}$, left, Example of an action potential burst elicited in a L3-6 BC by carbachol, which was preceded by a depolarization ramp with a simultaneous increase in sEPSP activity. Right, An expanded view of the burst illustrated in the left panel, showing the development of a depolarizing plateau, which was associated with inactivation of the $\mathrm{Na}^{+}$spike mechanisms. The relatively brief downward deflections in the membrane potential here and in $\boldsymbol{C}, \boldsymbol{D}$ are the responses to hyperpolarizing current steps used to monitor recording conditions, as well as the cells input resistance and time constant. $\boldsymbol{C}$, left panel, Example of an action potential burst evoked by carbachol that was not preceded by a depolarizing ramp. Right panel, An expanded view of the left panel showing that this burst was not associated with spike inactivation and depolarization plateau, but showed a decay in the membrane potential before a subsequent burst was elicited in the presence of carbachol. $\boldsymbol{D}$, Example traces showing recordings from a $\mathrm{PV}^{+} \mathrm{L} 3-6 \mathrm{BC}$ during the baseline period (left panel), after addition of carbachol (20 $\mu \mathrm{M}$, middle panel), and after addition of CNQX (10 $\mu \mathrm{M}$, right panel). Note that shortly after the addition of CNQX, bursting activity, the plateau depolarization, and the sEPSPs were all abolished.

sEPSCs recorded from $\mathrm{PV}^{+}$neurons. The effects of carbachol on PFC PNs are generally stronger in deeper layers (Obermayer et al., 2017; Radnikow and Feldmeyer, 2018). Moreover, most of these effects are mediated by stimulation of mAChRs, particularly of the M1 subtype (Gulledge et al., 2009; Dembrow et al., 2010; Baker et al., 2018). Thus, we predicted that carbachol would increase the excitatory drive onto $\mathrm{PV}^{+}$neurons via $\mathrm{M} 1 \mathrm{mAChR}$ activation and have stronger effects in deep cortical layers, where carbachol is more likely to elicit PN firing. Our data are consistent with these predictions, since we found that carbachol increased the excitatory drive selectively in
$\mathrm{PV}^{+} \mathrm{BC}$ of L3-6, and the effect was blocked by the broad spectrum mAChR antagonist atropine or by the M1selective mAChR antagonist pirenzepine.

The sources of excitatory synaptic input onto $\mathrm{PV}^{+}$neurons in PFC have not been well characterized; thus, it was not possible to predict whether carbachol would affect the excitatory drive differentially onto ChCs and BCs. In $\mathrm{PV}^{+}$neurons from mouse PFC, EPSCs can originate from nearby PNs (Pafundo et al., 2013; Yang et al., 2014; Lu et al., 2017) or from long-range inputs arriving from the contralateral PFC, hippocampus, amygdala, or mediodorsal thalamus (McGarry and Carter, 2016; Bogart and 
O'Donnell, 2018). Importantly, some data indicate that transmission at long-range excitatory inputs is suppressed by mAChR activation (Picciotto et al., 2012), although ACh neuromodulation may also downregulate local excitatory synaptic input from PNs onto other PNs (Tsodyks and Markram, 1997) or onto $\mathrm{PV}^{+}$cells (Levy et al., 2008). Thus, it seems likely that carbachol increases the excitatory drive onto $\mathrm{PV}^{+}$neurons primarily by facilitating the firing of neighboring PNs located in the PFC brain slices. Consistent with this possibility, we found that carbachol produced a strong suprathreshold depolarization and readily evoked action potential firing in L3-5 PNs. In mouse PFC, PNs provide strong excitatory input to $\mathrm{PV}^{+}$ BCs, and, albeit with lower probability, onto a subpopulation of ChCs that are PV-negative (Taniguchi et al., 2013; Lu et al., 2017). Whether $\mathrm{PV}^{+}$ChCs also receive significant input from local PNs remains unclear. The data reported here suggest that carbachol increases the excitatory drive onto $\mathrm{PV}^{+}$neurons by facilitating the firing of a subset of PNs that innervate L3-6 $\mathrm{PV}^{+} \mathrm{BCs}$, but not L2 $\mathrm{BCs}$ or ChCs. The effects of carbachol on PNs are stronger in deeper PFC layers (Obermayer et al., 2017; Radnikow and Feldmeyer, 2018), and we found that carbachol stimulates the firing of PNs located in deep layers. Thus, it is likely that the increase in excitatory drive onto L3-6 $\mathrm{BCs}$ originated from deep layer PNs. The local axon collaterals from deep layer PNs project mostly within deep layers (Markram et al., 2015; Reimann et al., 2017), and their projections to layers 1 and 2 (Fig. 10A) are very limited (Markram et al., 2015; Reimann et al., 2017). Therefore, the laminar distribution of $\mathrm{PV}^{+}$neuron dendrites reported here suggests that only L3-6 BCs have dendritic trees overlapping with the innervation fields from deep layer PNs. These morphologic properties are consistent with the idea that the increase in excitatory drive onto deep layer $\mathrm{BCs}$ originates from carbachol stimulation of PN firing in deep layers. As mentioned above, PNs provide input onto ChCs that are PV-negative and are mostly located in PFC layers 5 and 6 (Taniguchi et al., 2013). However, we did not study the PV-negative ChCs, since we recorded exclusively from $\mathrm{PV}^{+}$neurons (genetically labeled with GFP), and all the GFP+ cells in layers 3-6 were BCs. Therefore, the effects of carbachol on the $\mathrm{PV}$-negative subpopulation of deep layer $\mathrm{ChCs}$ remain to be determined.

Whereas carbachol, a carbamate analog of ACh resistant to hydrolysis by cholinesterases, is an agonist at both muscarinic and nicotinic AChRs, the stimulation by carbachol of PN firing in PFC is mediated by mAChRs (Gulledge et al., 2009; Obermayer et al., 2017; Baker et al., 2018; Radnikow and Feldmeyer, 2018). Moreover, in PFC, $\mathrm{mAChRs}$ also mediate the increase in $\mathrm{PV}^{+}$neuron excitability by carbachol (Pafundo et al., 2013). Our finding that the increase in excitatory drive onto $\mathrm{PV}^{+} \mathrm{BC}$ in L3-6 was prevented by $\mathrm{mAChR}$ antagonists (atropine or pirenzepine) is therefore consistent with previous observations that many of the effects of carbachol in neocortex, and specifically in PFC, are mediated by mAChRs.

\section{Activation of mAChRs stimulates L3-5 PN firing directly and stimulates L3-6 BC firing indirectly, via glutamate synapses}

Our findings that tetrodotoxin and pirenzepine block the carbachol-induced increase in excitatory drive onto L3-6 $\mathrm{BCs}$ are consistent with the idea that $\mathrm{M} 1 \mathrm{mAChR}$ activation stimulates firing of PNs that are a source of excitatory input onto L3-6 BCs. Here we found that M1 mAChR stimulation by carbachol elicits PN firing, as in previous studies (Gulledge and Stuart, 2005; Carr and Surmeier, 2007), and, moreover that most ( $86 \%$ ) of the L3-5 PNs showed direct excitation by M1 mAChR activation. The large percentage observed here of PNs directly stimulated by carbachol, and previous studies showing that local PNs are a significant source of excitatory input onto $\mathrm{PV}^{+}$ BCs (Pafundo et al., 2013; Yang et al., 2014; Lu et al., 2017) support the idea that the increase in excitatory drive onto L3-6 BCs results from stimulating firing in nearby PNs. In a previous study of mouse PFC, carbachol evoked firing in a minority $(\sim 30 \%)$ of the recorded PNs (Pafundo et al., 2013), contrasting with the $\sim 86 \%$ reported here. This discrepancy may be explained by the layer-dependent effects of cholinergic neuromodulation, since here we studied PNs in deep layers 3-5, versus mid/ superficial layer 3 neurons in the previous study (Pafundo et al., 2013). Furthermore, here, but not in the previous study (Pafundo et al., 2013), we superfused the recording chamber at high flow rate, a condition that enhances the magnitude and stability of the effects of carbachol in brain slices (Hajos et al., 2009).

The increases in SEPSC frequency and amplitude in L3-6 BCs by carbachol seem to reflect the stimulation of PN firing, since they were abolished by application of tetrodotoxin. Because single presynaptic PN axons establish multiple synapses with each postsynaptic $\mathrm{PV}^{+}$cell (Krimer and Goldman-Rakic, 2001; Wang et al., 2002), action potential firing in a PN simultaneously activates multiple synapses onto the $\mathrm{PV}^{+}$cell, producing EPSCs larger than those resulting from release at single synapses. Thus, the increase in SEPSC amplitude observed here may be caused by an increased proportion of sEPSCs produced by simultaneous release from multiple synapses when carbachol stimulates PN firing. Importantly, in studies of synaptically-connected pairs (Levy et al., 2008; Pafundo et al., 2013) carbachol decreased the amplitude of the first response evoked in $\mathrm{PV}^{+}$neurons by stimulus trains in nearby presynaptic PNs, while having small or no effect on subsequent responses that display short-term depression (Levy et al., 2008; Pafundo et al., 2013). Together, the data suggest that in addition to stimulating the firing of $\mathrm{PNs}$ presynaptic to $\mathrm{PV}^{+}$cells, $\mathrm{mAChR}$ activation modulates presynaptic action potential-dependent glutamate release mechanisms, and in a manner that may optimize $\mathrm{PN}$-to- $\mathrm{PV}^{+}$cell synaptic transmission during repetitive PN firing (Levy et al., 2008; Pafundo et al., 2013).

Previous studies of $\mathrm{PV}^{+}$neurons in mouse PFC suggested that AChR activation does not directly depolarize or hyperpolarize the membrane of $\mathrm{PV}^{+}$neurons (Kawaguchi, 1997; Gulledge et al., 2007; Pafundo et al., 2013; Yi et al., 2014). In contrast, other studies reported varying 
effects of $\mathrm{AChR}$ stimulation on $\mathrm{PV}^{+}$cells, including a hyperpolarizing effect that may inhibit $\mathrm{PV}^{+}$neuron activity. Many of these effects were characterized in other cortical regions (Xiang et al., 1998; Yi et al., 2014; Bell et al., 2015; Yi et al., 2015; Wenger Combremont et al., 2016), and the AChR effects in $\mathrm{PV}^{+}$neurons from PFC have been assessed in only a limited number of studies. We therefore tested the effects of carbachol on the membrane potential and excitability of $\mathrm{PV}^{+}$neurons in mouse PFC with synaptic transmission blocked. We found that carbachol depolarized the L3-6 BCs via mAChR activation, but the depolarization was small and did not evoke action potential firing, in contrast to the direct suprathreshold effect observed in L3-5 PNs. To block excitatory synaptic transmission, we used the non-NMDA glutamate receptor antagonist CNQX. Thus, we cannot rule out that PN firing stimulated by carbachol increases glutamate release and activates NMDA or metabotropic glutamate receptors mediating the depolarization produced in the presence of CNQX. However, NMDA receptors are unlikely to mediate such depolarization in $\mathrm{PV}^{+}$neurons because in these neurons NMDA receptor-mediated synaptic currents are very small relative to non-NMDA responses (Rotaru et al., 2011; Bogart and O'Donnell, 2018). Interestingly, $\mathrm{PV}^{+}$neurons display a tonic NMDA receptor-mediated current that could contribute to the depolarization observed in the present experiments, although at negative membrane potentials such as those studied here, the tonic NMDA current is small (Povysheva and Johnson, 2012). We additionally tested the prediction that the enhanced excitatory drive, likely combined with the depolarization and increased excitability of $\mathrm{PV}^{+}$neurons, may elicit L3-6 BC firing. We found that carbachol application with glutamate synaptic transmission intact evoked firing in $85 \%(11 / 13)$ of the L3-6 BCs. In contrast, only $11 \%(1 / 9)$ of the L3-6 BCs fired in response to carbachol application when glutamatergic transmission was blocked, demonstrating the capacity of the carbacholinduced excitatory drive to recruit L3-6 BC activity.

\section{Functional consequences of mAChR-mediated potentiation of excitatory drive onto $\mathrm{PV}^{+} \mathrm{BCs}$}

$\mathrm{PV}^{+}$neuron activation by excitatory synaptic input is crucial to generate $\gamma$ oscillations in the pyramidalinterneuron- $\gamma$-network (PING) model (Fisahn et al., 1998; Whittington et al., 2000). In the PING model, which is supported by empirical data (Hajos and Paulsen, 2009; Sohal et al., 2009; Buzsáki and Wang, 2012; Neske et al., 2015; Salkoff et al., 2015), $\mathrm{PV}^{+}$neuron recruitment by synaptic input from nearby PNs generates the rhythmic feedback inhibition that synchronizes the PN network (Whittington et al., 2000; Börgers and Kopell, 2003; Borgers, 2017). $\gamma$ Oscillations are prominent in mouse PFC (Ruiz-Mejias et al., 2011; Cho et al., 2015; Howe et al., 2017; Cao et al., 2018), seem to preferentially involve BCs relative to ChCs (Gulyás et al., 2010; Dugladze et al., 2012; Massi et al., 2012), and depend on mAChRs (Rodriguez et al., 2004, 2010; Janiesch et al., 2011; Howe et al., 2017). Therefore, our current data suggest the prediction, to be tested in future studies, that the enhancement of excitatory input onto $\mathrm{PV}^{+} \mathrm{BCs}$ is a mech- anism by which mAChR activation contributes to $\gamma$ oscillation production.

$\gamma$ Band synchrony is thought to be crucial for transmission of information between cortical areas (Fries, 2015). Thus, if the enhanced excitatory input onto $\mathrm{PV}^{+} \mathrm{BCs}$ contributes to $\gamma$ oscillation production, this could be an important process by which cholinergic neuromodulation supports cognitive function. Consistent with a crucial role of ACh-mediated neuromodulation, a deficit in cholinergic signaling is thought to contribute to the pathophysiology of various psychiatric illnesses that impair cognition, in particular schizophrenia (Higley and Picciotto, 2014). Moreover, mAChRs, specifically of the M1 subtype shown here to mediate many of the cholinergic effects in PFC, have been suggested as a potential target for schizophrenia treatment (Jones et al., 2012; Yohn and Conn, 2018). Alterations in $\gamma$ oscillations and $\mathrm{PV}^{+}$neurons in the PFC are a central feature in schizophrenia pathophysiology (Lewis, 2014). Thus, an interesting possibility is that abnormal M1 mAChR-mediated signaling (Scarr et al., 2018) is involved in the alterations in $\mathrm{PV}^{+}$neurons, network oscillations, and cognition in schizophrenia.

\section{References}

Arnsten AF, Wang M (2016) Targeting prefrontal cortical systems for drug development: potential therapies for cognitive disorders. Annu Rev Pharmacol Toxicol 56:339-360. CrossRef Medline

Baker AL, O'Toole RJ, Gulledge AT (2018) Preferential cholinergic excitation of corticopontine neurons. J Physiol 596:1659-1679. CrossRef

Ballinger EC, Ananth M, Talmage DA, Role LW (2016) Basal forebrain cholinergic circuits and signaling in cognition and cognitive decline. Neuron 91:1199-1218. CrossRef Medline

Bell LA, Bell KA, McQuiston AR (2015) Activation of muscarinic receptors by ACh release in hippocampal CA1 depolarizes VIP but has varying effects on parvalbumin-expressing basket cells. J Physiol 593:197-215. CrossRef

Bogart LJ, O’Donnell P (2018) Multiple long-range inputs evoke NMDA currents in prefrontal cortex fast-spiking interneurons. Neuropsychopharmacology 43:2101-2108. CrossRef Medline

Borgers C (2017) The PING model of gamma rhythms. In: An introduction to modeling neuronal dynamics (Borgers C, ed), pp 255267. New York: Springer International Publishing.

Börgers C, Kopell N (2003) Synchronization in networks of excitatory and inhibitory neurons with sparse, random connectivity. Neural Comput 15:509-538. CrossRef Medline

Buchanan KA, Blackman AV, Moreau AW, Elgar D, Costa RP, Lalanne T, Tudor Jones AA, Oyrer J, Sjöström PJ (2012) Targetspecific expression of presynaptic NMDA receptors in neocortical microcircuits. Neuron 75:451-466. CrossRef Medline

Buzsáki G, Wang XJ (2012) Mechanisms of gamma oscillations. Annu Rev Neurosci 35:203-225. CrossRef Medline

Cao W, Lin S, Xia QQ, Du YL, Yang Q, Zhang MY, Lu YQ, Xu J, Duan SM, Jun X, Feng G, Xu J, Luo JH (2018) Gamma oscillation dysfunction in mPFC leads to social deficits in neuroligin $3 \mathrm{R} 451 \mathrm{C}$ knockin mice. Neuron 97:1253-1260. CrossRef

Carr DB, Surmeier DJ (2007) M1 muscarinic receptor modulation of Kir2 channels enhances temporal summation of excitatory synaptic potentials in prefrontal cortex pyramidal neurons. J Neurophysiol 97:3432-3438. CrossRef Medline

Chattopadhyaya B, Di Cristo G, Higashiyama H, Knott GW, Kuhlman SJ, Welker E, Huang ZJ (2004) Experience and activity-dependent maturation of perisomatic GABAergic innervation in primary visual cortex during a postnatal critical period. J Neurosci 24:9598-9611. CrossRef 
Cho KK, Hoch R, Lee AT, Patel T, Rubenstein JL, Sohal VS (2015) Gamma rhythms link prefrontal interneuron dysfunction with cognitive inflexibility in DIx5/6(+/-) mice. Neuron 85:1332-1343. CrossRef Medline

Croxson PL, Kyriazis DA, Baxter MG (2011) Cholinergic modulation of a specific memory function of prefrontal cortex. Nat Neurosci 14:1510-1512. CrossRef Medline

DeFelipe J, López-Cruz PL, Benavides-Piccione R, Bielza C, Larrañaga $P$, Anderson $S$, Burkhalter A, Cauli B, Fairén A, Feldmeyer D, Fishell G, Fitzpatrick D, Freund TF, González-Burgos G, Hestrin S, Hill S, Hof PR, Huang J, Jones EG, Kawaguchi Y, et al. (2013) New insights into the classification and nomenclature of cortical GABAergic interneurons. Nat Rev Neurosci 14:202-216. CrossRef Medline

Dembrow NC, Chitwood RA, Johnston D (2010) Projection-specific neuromodulation of medial prefrontal cortex neurons. J Neurosci 30:16922-16937. CrossRef Medline

Ding DC, Gabbott PL, Totterdell S (2001) Differences in the laminar origin of projections from the medial prefrontal cortex to the nucleus accumbens shell and core regions in the rat. Brain Res 917:81-89. Medline

Dugladze T, Schmitz D, Whittington MA, Vida I, Gloveli T (2012) Segregation of axonal and somatic activity during fast network oscillations. Science 336:1458-1461. CrossRef Medline

Fisahn A, Pike FG, Buhl EH, Paulsen O (1998) Cholinergic induction of network oscillations at $40 \mathrm{~Hz}$ in the hippocampus in vitro. Nature 394:186-189. CrossRef Medline

Fries $\mathrm{P}$ (2015) Rhythms for cognition: communication through coherence. Neuron 88:220-235. CrossRef Medline

Gabbott PL, Dickie BG, Vaid RR, Headlam AJ, Bacon SJ (1997) Local-circuit neurones in the medial prefrontal cortex (areas 25, 32 and $24 \mathrm{~b}$ ) in the rat: morphology and quantitative distribution. J Comp Neurol 377:465-499. Medline

Gulledge AT, Stuart GJ (2005) Cholinergic inhibition of neocortical pyramidal neurons. J Neurosci 25:10308-10320. CrossRef Medline

Gulledge AT, Park SB, Kawaguchi Y, Stuart GJ (2007) Heterogeneity of phasic cholinergic signaling in neocortical neurons. J Neurophysiol 97:2215-2229. CrossRef Medline

Gulledge AT, Bucci DJ, Zhang SS, Matsui M, Yeh HH (2009) M1 receptors mediate cholinergic modulation of excitability in neocortical pyramidal neurons. J Neurosci 29:9888-9902. CrossRef Medline

Gulyás Al, Megías M, Emri Z, Freund TF (1999) Total number and ratio of excitatory and inhibitory synapses converging onto single interneurons of different types in the CA1 area of the rat hippocampus. J Neurosci 19:10082-10097. CrossRef

Gulyás Al, Szabó GG, Ulbert I, Holderith N, Monyer H, Erdélyi F, Szabó G, Freund TF, Hájos N (2010) Parvalbumin-containing fastspiking basket cells generate the field potential oscillations induced by cholinergic receptor activation in the hippocampus. J Neurosci 30:15134-15145. CrossRef Medline

Hajos N, Paulsen O (2009) Network mechanisms of gamma oscillations in the CA3 region of the hippocampus. Neural Netw 22:11131119. CrossRef Medline

Hajos N, Papp EC, Acsady L, Levey Al, Freund TF (1998) Distinct interneuron types express $\mathrm{m} 2$ muscarinic receptor immunoreactivity on their dendrites or axon terminals in the hippocampus. Neuroscience 82:355-376. Medline

Hajos N, Ellender TJ, Zemankovics R, Mann EO, Exley R, Cragg SJ, Freund TF, Paulsen O (2009) Maintaining network activity in submerged hippocampal slices: importance of oxygen supply. Eur $\mathrm{J}$ Neurosci 29:319-327. CrossRef Medline

Hedrick T, Waters J (2015) Acetylcholine excites neocortical pyramidal neurons via nicotinic receptors. J Neurophysiol 113:21952209. CrossRef Medline

Higley MJ, Picciotto MR (2014) Neuromodulation by acetylcholine: examples from schizophrenia and depression. Curr Opin Neurobiol 29:88-95. CrossRef Medline
Howe WM, Gritton HJ, Lusk NA, Roberts EA, Hetrick VL, Berke JD, Sarter M (2017) Acetylcholine release in prefrontal cortex promotes gamma oscillations and theta-gamma coupling during cue detection. J Neurosci 37:3215-3230. CrossRef Medline

$\mathrm{Hu} \mathrm{H}$, Gan J, Jonas P (2014) Interneurons. Fast-spiking, parvalbu$\min (+)$ GABAergic interneurons: from cellular design to microcircuit function. Science 345:1255263. CrossRef Medline

Inan M, Blazquez-Llorca L, Merchan-Perez A, Anderson SA, DeFelipe J, Yuste R (2013) Dense and overlapping innervation of pyramidal neurons by chandelier cells. J Neurosci 33:1907-1914. CrossRef

Janiesch PC, Krüger HS, Pöschel B, Hanganu-Opatz IL (2011) Cholinergic control in developing prefrontal-hippocampal networks. J Neurosci 31:17955-17970. CrossRef Medline

Jones CK, Byun N, Bubser M (2012) Muscarinic and nicotinic acetylcholine receptor agonists and allosteric modulators for the treatment of schizophrenia. Neuropsychopharmacology 37:16-42. CrossRef Medline

Joshi A, Kalappa BI, Anderson CT, Tzounopoulos T (2016) Cellspecific cholinergic modulation of excitability of layer 5B principal neurons in mouse auditory cortex. J Neurosci 36:8487-8499. CrossRef Medline

Kameda H, Hioki H, Tanaka YH, Tanaka T, Sohn J, Sonomura T, Furuta T, Fujiyama F, Kaneko T (2012) Parvalbumin-producing cortical interneurons receive inhibitory inputs on proximal portions and cortical excitatory inputs on distal dendrites. Eur J Neurosci 35:838-854. CrossRef Medline

Kawaguchi $Y$ (1997) Selective cholinergic modulation of cortical GABAergic cell subtypes. J Neurophysiol 78:1743-1747. CrossRef Medline

Klausberger T, Somogyi P (2008) Neuronal diversity and temporal dynamics: the unity of hippocampal circuit operations. Science 321:53-57. CrossRef Medline

Krimer LS, Goldman-Rakic PS (2001) Prefrontal microcircuits: membrane properties and excitatory input of local, medium, and wide arbor interneurons. J Neurosci 21:3788-3796. Medline

Levy RB, Reyes AD, Aoki C (2008) Cholinergic modulation of local pyramid-interneuron synapses exhibiting divergent short-term dynamics in rat sensory cortex. Brain Res 1215:97-104. CrossRef Medline

Lewis DA (2014) Inhibitory neurons in human cortical circuits: substrate for cognitive dysfunction in schizophrenia. Curr Opin Neurobiol 26:22-26. CrossRef Medline

Lu J, Tucciarone J, Padilla-Coreano N, He M, Gordon JA, Huang ZJ (2017) Selective inhibitory control of pyramidal neuron ensembles and cortical subnetworks by chandelier cells. Nat Neurosci 20: 1377-1383. CrossRef Medline

Markram H, Muller E, Ramaswamy S, Reimann MW, Abdellah M, Sanchez CA, Ailamaki A, Alonso-Nanclares L, Antille N, Arsever S, Kahou GA, Berger TK, Bilgili A, Buncic N, Chalimourda A, Chindemi G, Courcol JD, Delalondre F, Delattre V, Druckmann S, et al. (2015) Reconstruction and simulation of neocortical microcircuitry. Cell 163:456-492. CrossRef Medline

Massi L, Lagler M, Hartwich K, Borhegyi Z, Somogyi P, Klausberger $T$ (2012) Temporal dynamics of parvalbumin-expressing axoaxonic and basket cells in the rat medial prefrontal cortex in vivo. J Neurosci 32:16496-16502. CrossRef Medline

McCormick DA, Prince DA (1986) Mechanisms of action of acetylcholine in the guinea-pig cerebral cortex in vitro. J Physiol 375: 169-194. Medline

McGarry LM, Carter AG (2016) Inhibitory gating of basolateral amygdala inputs to the prefrontal cortex. J Neurosci 36:9391. CrossRef Medline

Miyamae T, Chen K, Lewis DA, Gonzalez Burgos G (2017) Distinct physiological maturation of parvalbumin-positive neuron subtypes in mouse prefrontal cortex. J Neurosci 37:4883-4902. CrossRef Medline

Muñoz W, Rudy B (2014) Spatiotemporal specificity in cholinergic control of neocortical function. Curr Opin Neurobiol 26:149-160. CrossRef Medline 
Neske GT, Patrick SL, Connors BW (2015) Contributions of diverse excitatory and inhibitory neurons to recurrent network activity in cerebral cortex. J Neurosci 35:1089-1105. CrossRef Medline

Obermayer J, Verhoog MB, Luchicchi A, Mansvelder HD (2017) Cholinergic modulation of cortical microcircuits is layer-specific: evidence from rodent, monkey and human brain. Front Neural Circuits 11:100. CrossRef Medline

Oda S, Tsuneoka Y, Yoshida S, Adachi-Akahane S, Ito M, Kuroda M, Funato H (2018) Immunolocalization of muscarinic M1 receptor in the rat medial prefrontal cortex. J Comp Neurol 526:1329-1350. CrossRef Medline

Pafundo DE, Miyamae T, Lewis DA, Gonzalez-Burgos G (2013) Cholinergic modulation of neuronal excitability and recurrent excitation-inhibition in prefrontal cortex circuits: implications for gamma oscillations. J Physiol 591:4725-4728. CrossRef Medline

Pafundo DE, Miyamae T, Lewis DA, Gonzalez-Burgos G (2018) Presynaptic effects of $\mathrm{N}$-methyl-D-aspartate receptors enhance parvalbumin cell-mediated inhibition of pyramidal cells in mouse prefrontal cortex. Biol Psychiatry 84:460-470. CrossRef Medline

Paul A, Crow M, Raudales R, He M, Gillis J, Huang ZJ (2017) Transcriptional architecture of synaptic communication delineates GABAergic neuron identity. Cell 171:522-539.e20. CrossRef

Picciotto MR, Higley MJ, Mineur YS (2012) Acetylcholine as a neuromodulator: cholinergic signaling shapes nervous system function and behavior. Neuron 76:116-129. CrossRef Medline

Poorthuis RB, Bloem B, Schak B, Wester J, de Kock CP, Mansvelder HD (2013) Layer-specific modulation of the prefrontal cortex by nicotinic acetylcholine receptors. Cereb Cortex 23:148-161. CrossRef Medline

Povysheva NV, Johnson JW (2012) Tonic NMDA receptor-mediated current in prefrontal cortical pyramidal cells and fast-spiking interneurons. J Neurophysiol 107:2232-2243. CrossRef Medline

Radnikow G, Feldmeyer D (2018) Layer- and cell type-specific modulation of excitatory neuronal activity in the neocortex. Front Neuroanat 12:1. CrossRef Medline

Reimann MW, Horlemann AL, Ramaswamy S, Muller EB, Markram H (2017) Morphological diversity strongly constrains synaptic connectivity and plasticity. Cereb Cortex 27:4570-4585.

Rodriguez R, Kallenbach U, Singer W, Munk MH (2004) Short- and long-term effects of cholinergic modulation on gamma oscillations and response synchronization in the visual cortex. J Neurosci 24:10369-10378. CrossRef

Rodriguez R, Kallenbach U, Singer W, Munk MH (2010) Stabilization of visual responses through cholinergic activation. Neuroscience 165:944-954. CrossRef Medline

Rotaru DC, Yoshino H, Lewis DA, Ermentrout GB, Gonzalez-Burgos G (2011) Glutamate receptor subtypes mediating synaptic activation of prefrontal cortex neurons: relevance for schizophrenia. $\mathrm{J}$ Neurosci 31:142-156. CrossRef Medline

Ruiz-Mejias M, Ciria-Suarez L, Mattia M, Sanchez-Vives MV (2011) Slow and fast rhythms generated in the cerebral cortex of the anesthetized mouse. J Neurophysiol 106:2910-2921. CrossRef Medline

Salkoff DB, Zagha E, Yüzgeç O, McCormick DA (2015) Synaptic mechanisms of tight spike synchrony at gamma frequency in cerebral cortex. J Neurosci 35:10236-10251. CrossRef Medline

Scarr E, Hopper S, Vos V, Seo MS, Everall IP, Aumann TD, Chana G, Dean B (2018) Low levels of muscarinic M1 receptor-positive neurons in cortical layers III and V in Brodmann areas 9 and 17 from individuals with schizophrenia. J Psychiatry Neurosci 43: 338-346. CrossRef
Sippy T, Yuste R (2013) Decorrelating action of inhibition in neocortical networks. J Neurosci 33:9813-9830. CrossRef Medline

Sohal VS, Zhang F, Yizhar O, Deisseroth K (2009) Parvalbumin neurons and gamma rhythms enhance cortical circuit performance. Nature 459:698-702. CrossRef Medline

Somogyi P, Tamás G, Lujan R, Buhl EH (1998) Salient features of synaptic organisation in the cerebral cortex. Brain Res Reviews 26:113-135. Medline

Taniguchi H, Lu J, Huang ZJ (2013) The spatial and temporal origin of chandelier cells in mouse neocortex. Science 339:70-74. CrossRef Medline

Tsodyks MV, Markram H (1997) The neural code between neocortical pyramidal neurons depends on neurotransmitter release probability. Proc Natl Acad Sci USA 94:719-723. Medline

Van De Werd HJ, Rajkowska G, Evers P, Uylings HB (2010) Cytoarchitectonic and chemoarchitectonic characterization of the prefrontal cortical areas in the mouse. Brain Struct Funct 214:339353. CrossRef Medline

Viney TJ, Lasztoczi B, Katona L, Crump MG, Tukker JJ, Klausberger T, Somogyi P (2013) Network state-dependent inhibition of identified hippocampal CA3 axo-axonic cells in vivo. Nat Neurosci 16:1802-1811. CrossRef Medline

Wang Y, Gupta A, Toledo-Rodriguez M, Wu CZ, Markram H (2002) Anatomical, physiological, molecular and circuit properties of nest basket cells in the developing somatosensory cortex. Cereb Cortex 12:395-410. Medline

Wenger Combremont AL, Bayer L, Dupré A, Mühlethaler M, Serafin M (2016) Effects of hypocretin/orexin and major transmitters of arousal on fast spiking neurons in mouse cortical layer 6B. Cereb Cortex 26:3553-3562. CrossRef Medline

Whittington MA, Traub RD, Kopell N, Ermentrout B, Buhl EH (2000) Inhibition-based rhythms: experimental and mathematical observations on network dynamics. Int J Psychophysiol 38:315-336. Medline

Woodruff AR, McGarry LM, Vogels TP, Inan M, Anderson SA, Yuste $R$ (2011) State-dependent function of neocortical chandelier cells. J Neurosci 31:17872-17886. CrossRef Medline

Xiang Z, Huguenard JR, Prince DA (1998) Cholinergic switching within neocortical inhibitory networks. Science 281:985-988. Medline

Yang JM, Zhang J, Yu YQ, Duan S, Li XM (2014) Postnatal development of 2 microcircuits involving fast-spiking interneurons in the mouse prefrontal cortex. Cereb Cortex 24:98-109. CrossRef Medline

Yi F, Ball J, Stoll KE, Satpute VC, Mitchell SM, Pauli JL, Holloway BB, Johnston AD, Nathanson NM, Deisseroth K, Gerber DJ, Tonegawa S, Lawrence JJ (2014) Direct excitation of parvalbumin-positive interneurons by M1 muscarinic acetylcholine receptors: roles in cellular excitability, inhibitory transmission and cognition. J Physiol 592:3463-3494. CrossRef Medline

Yi F, DeCan E, Stoll K, Marceau E, Deisseroth K, Lawrence JJ (2015) Muscarinic excitation of parvalbumin-positive interneurons contributes to the severity of pilocarpine-induced seizures. Epilepsia 56:297-309. CrossRef Medline

Yohn SE, Conn PJ (2018) Positive allosteric modulation of M1 and M4 muscarinic receptors as potential therapeutic treatments for schizophrenia. Neuropharmacology 136:438-448. CrossRef Medline

Zhu Y, Stornetta RL, Zhu JJ (2004) Chandelier cells control excessive cortical excitation: characteristics of whisker-evoked synaptic responses of layer $2 / 3$ nonpyramidal and pyramidal neurons. $J$ Neurosci 24:5101-5108. CrossRef Medline 